\title{
Disagreement lost
}

\author{
Martín Abreu Zavaleta ${ }^{1}$
}

Received: 21 January 2020 / Accepted: 5 September 2020 / Published online: 16 September 2020 (c) The Author(s) 2020

\begin{abstract}
This paper develops a puzzle about non-merely-verbal disputes. At first sight, it would seem that a dispute over the truth of an utterance is not merely verbal only if there is a proposition that the parties to the dispute take the utterance under dispute to express, which one of the parties accepts and the other rejects. Yet, as I argue, it is extremely rare for ordinary disputes over an utterance's truth to satisfy this condition, in which case non-merely verbal disputes are extremely rare. After examining various responses to the puzzle, I outline a solution using the framework of truthmaker semantics.
\end{abstract}

Keywords Disagreement · Truthmaker semantics · Verbal disputes

\section{Introduction}

Think of disputes as linguistic interactions (as opposed to, say, conflicts in people's attitudes). ${ }^{1}$ So understood, it is enough for two people to have a dispute over the truth of a given utterance that one of them makes that utterance and the other rejects ite.g. by saying 'that's not true', 'that's false', 'you're wrong', or something along those lines. Since two people may have a dispute over the truth of a given utterance without having conflicting beliefs about the facts they take that utterance to be about, we can make a broad division between disputes that are merely verbal and disputes that are not. If the parties to a dispute over the truth of a certain utterance have conflicting beliefs about whether the utterance is true, but non-conflicting beliefs about the facts which they take the utterance to be about, then their dispute is purely about whether

\footnotetext{
1 Cf. Cappelen and Hawthorne's (2009) distinction between disagreement as an activity and disagreement as a state.
}

Parts of this paper were written while holding a postdoctoral fellowship from Coordinación de Humanidades, at Universidad Nacional Autónoma de México. I thank them for their generous support.

$凶 \quad$ Martín Abreu Zavaleta

martin.abreu@umu.se,maz275@nyu.edu

1 Department of Historical, Philosophical, and Religious Studies, Umeå universitet, A, Humanisthuset, HF127, 90187 Umeå, Sweden 
the utterance is true, and in that sense it is merely verbal. But if the parties to the dispute have conflicting beliefs both about whether the utterance is true and about the facts which they take the utterance to be about, their dispute is not merely verbal. ${ }^{2}$

For example, suppose that Anna utters 'Carla's house is green' and Bob replies 'that's not true'. Other things being equal, Anna and Bob's dispute reflects a conflict in their beliefs about whether Anna's utterance is true: Anna believes that it is, but Bob believes that it isn't. If, in addition, Anna and Bob both believe that Anna's utterance means that Carla's house is green, then their dispute also betrays a conflict in their beliefs about the color of Anna's house, and in that sense is not merely verbal; by uttering 'Carla's house is green', Anna expressed her belief that Carla's house is green, whereas, by uttering 'that's not true', Bob expressed his belief that Carla's house is not green. But if, on the other hand, Anna believes that her utterance means that Carla's house is green, whereas Bob believes that it means that Carla's house is orange, then the conflict between Anna and Bob's beliefs about whether Anna's utterance is true doesn't amount to a conflict between their beliefs about the color of Anna's house. In that case, their dispute will be merely verbal.

This paper develops a puzzle about the kind of conflict that characterizes nonmerely-verbal disputes. At first sight, that kind of conflict just is the conflict between the belief that a certain proposition is true and the belief that the same proposition is false: disputes over the truth of a given utterance are not merely verbal just in case there is a proposition that the parties to the dispute believe the utterance to express, which one of the parties accepts and the other rejects. ${ }^{3}$ Yet, as I argue, it is extremely rare for ordinary disputes over an utterance's truth to satisfy this condition; thus, should we accept this seemingly natural proposal, it would be extremely rare for ordinary disputes not to be merely verbal.

This is a troubling result. First and foremost, it goes against the common sense view that typical disputes really betray conflicts in people's beliefs about substantive matters (e.g. the color of Anna's house), and not only a conflict in their beliefs about the purely linguistic matter of whether a certain utterance is true or not. Second, many times (in philosophy, for example) the point of engaging in a dispute is to discover the truth about the facts we take the utterance to be about. Yet if the beliefs people express in disputes over an utterance's truth are typically not in conflict, it is not clear that participating in those disputes should take us closer to the truth about the facts we take those utterances to be about. After all, if by uttering 'Carla's house is green' Anna expressed her belief that Carla's house is green and by uttering 'that's not true' Bob expressed his belief that Carla's house is not orange, it is unclear whether there is any point in having a dispute over the truth of Anna's utterance at all, or whether (despite Anna and Bob's best intentions) having such a dispute would in any way help Anna or Bob discover the truth about the color of Anna's house. I argue that, in order to avoid this troubling result, we should adopt a new and relatively radical account of the kind of conflict in beliefs that characterizes non-merely-verbal disputes.

\footnotetext{
2 See Jenkins (2014) for discussion.

3 As is standard, I assume that propositions are abstract entities which play various roles: they are the primary objects of truth and falsity, they are the contents of beliefs and thoughts, and the truth-conditional contents of utterances of declarative sentences.
} 
The structure of the paper is as follows. I start by motivating the thesis that disputes over the truth of an utterance are not merely verbal just in case there is a proposition that the parties to the dispute take that utterance to express (Sect. 2). Then I present the puzzle and argue that various seemingly natural responses are not successful (Sects. 3-5). Towards the end of the paper I outline a potential solution to the puzzle, discuss objections, and briefly discuss the puzzle's consequences for a debate between contextualists and anti-contextualists (Sects. 6-8).

\section{Disagreement in content}

As a starting point, it seems natural to think that the kind of conflict between beliefs that characterizes non-merely-verbal disputes just is the conflict between believing that a certain proposition is true and believing that the same proposition is false. Thus, what it is for a dispute over the truth of a certain utterance not to be merely verbal just is for there to be a proposition such that, by producing that utterance, the speaker expresses a belief that that proposition is true and, by rejecting that utterance, the objector expresses a belief that that proposition is false. Assuming that the proposition in which the speaker expresses a belief through a literal assertoric utterance just is the proposition she believes to be that utterance's truth-conditional content, we can capture this idea as follows:

Disagreement in Content: A dispute between A and B over the truth of $U$ is not merely verbal if and only if there is a proposition A and B both believe to be U's truth-conditional content. ${ }^{4}$

Here, we can understand an utterance's truth-conditional content as the possible-worlds proposition which is true in exactly the same worlds as the utterance, keeping the utterance's meaning fixed. In other words, where $\mathrm{U}$ is an utterance and $\mathrm{P}$ is a proposition, we can define truth-conditional content as follows:

TC-content: $\mathrm{U}$ has the truth-conditional content $\mathrm{P}$ just in case: the unique sentence $\mathrm{S}$ that $\mathrm{U}$ is an utterance of, the unique language $\mathrm{L}$ that $\mathrm{S}$ is in, and the unique context $\mathrm{c}$ that $\mathrm{U}$ occupies are such that, necessarily, $\mathrm{S}$ is true as used in $\mathrm{c}$ in $\mathrm{L}$ if and only if $\mathrm{P}$ is true. ${ }^{5,6}$

\footnotetext{
${ }^{4}$ Hirsch (1993, p. 181) endorses a similar characterization of non-merely-verbal disputes in terms of believed equivalences between sentences rather than in terms of beliefs about an utterance's truth-conditions. Sidelle (2007, p. 89) takes a similar characterization to be the standard picture of non-verbal disputes. MacFarlane (2007, p. 24) adopts a related characterization of disagreement in the preamble to his discussion of relativism.

5 Sentences here should be thought of as disambiguated sentences.

6 The definition is inspired by Lewis (1975) and Foster (1976). Note that the present definition remains neutral with respect to whether an utterance necessarily has the truth-conditional content it in fact has. On one hand, the definition is compatible with the claim that one and the same utterance could have occurred in a different context, or that it could have been an utterance of a sentence in a language other than the language it is actually in. As such, it is compatible with the present definition that one and the same utterance could have had a different truth-conditional content from the one it actually has. On the other hand, the present definition is also compatible with the claim that if an utterance is an utterance of a sentence in a certain language or it occurs in a certain context, that is necessarily so. If that is the case, it follows from the definition that any utterance has its actual truth-conditional content as a matter of necessity. Thanks to Cian Dorr and Jim Pryor for discussion.
} 
Importantly, beliefs about an utterance's truth-conditional are meant to be implicit, and ordinary language users need not be in a position to formulate them explicitly. ${ }^{7}$

Disagreement in Content delivers correct predictions in the two scenarios we have considered so far. Consider the case in which Anna believes that the word 'green' expresses the property of being green, but Bob believes that it expresses the property of being orange. Given Anna and Bob's beliefs about the meaning of the word 'green', they will differ in their beliefs about the truth-conditional content of Anna's utterance: given standard compositional principles, Anna will believe that her utterance has the truth-conditional content that Carla's house is green, whereas Bob will believe that the same utterance has the truth-conditional content that Carla's house is orange. Thus, according to Disagreement in Content, Anna and Bob's dispute is merely verbal. This is the right prediction since, given Anna and Bob's beliefs about the meaning of the word 'green', their respective utterances of 'Carla's house is green' and 'that's not true' do not express conflicting beliefs about the color of Anna's house.

On the other hand, if Anna and Bob both believe that 'green' expresses the property of being green, Disagreement in Content predicts that Anna and Bob's dispute is not merely verbal. For, given Anna and Bob's beliefs about the meaning of 'green' and standard compositional principles, Anna and Bob will both believe that Anna's utterance has the truth-conditional content that Carla's house is green. Once again, this is the right prediction: since Anna and Bob both believe that 'green' expresses the property of being green, their respective utterances of 'Carla's house is green' and 'that's not true' do express conflicting beliefs about the color of Anna's house.

For comparison, consider a view that characterizes the kind of conflict we are after in terms of the truth-conditional content that the utterance under dispute in fact hasas opposed to the truth-conditional content that the parties to the dispute believe that the utterance has. For example, that view could say that a dispute over the truth of a given utterance is not merely verbal just in case the uttered sentence has the same truthconditional content relative to all the disputant's respective languages and contexts. Since (i) Anna and Bob are both speaking English, (ii) Anna and Bob's beliefs about the meaning of 'green' make no difference to the actual meaning of 'green' in English (assuming a basic kind of externalism), and (iii) Anna and Bob are in the same context, the truth-conditional content of Anna's utterance remains the same regardless of what Anna and Bob believe that truth-conditional content to be. In particular, the truthconditional content of Anna's utterance remains the same regardless of whether both Anna and Bob believe that 'green' expresses the property of being green or one of them

\footnotetext{
7 I take on board the standard assumption that ordinary language users have implicit beliefs about the truth-conditional content of ordinary utterances. This assumption follows from three standard claims. First, that knowledge entails belief. Second, that competent language users know the meaning of utterances in the languages they are competent in. And third, that knowing the meaning of an utterance requires knowing its truth-conditions. For a version of this last assumption, see for instance (Heim and Kratzer 1998), who start their famous textbook by saying "To know the meaning of a sentence is to know its truth-conditions (p. 1). Portner (2005) also takes knowledge of truth-conditions to be the starting point for semantics: "The knowledge of meaning involves (at least) knowledge of the conditions under which a sentence is true, and those under which it's false" (p. 13). Larson and Segal (1995) motivate similar assumptions in their initial discussion of the relation between meaning and truth (pp. 5-7). Though Heim and Kratzer talk about knowledge of a sentence's (as opposed to an utterance's) truth-conditions, they do so only for the sake of simplicity, since they are ignoring the influence of context on a sentence's semantic content.
} 
believes that 'green' expresses the property of being orange. Thus, the present view predicts that Anna and Bob's dispute is not merely verbal even in the case in which Anna believes that 'green' expresses the property of being green and Bob believes that 'green' expresses the property of being orange. This, I have argued, is the wrong prediction.

Here is another example. Suppose that Anna utters 'water has alcohol' and that, due to an unorthodox upbringing, Anna believes that the English word 'water' refers to vodka. Bob, who believes that the English word 'water' refers to water, disputes the truth of Anna's utterance. Because Anna and Bob are both speaking English and the reference of the word 'water' in English is independent of Anna or Bob's beliefs (assuming a basic kind of semantic externalism), Anna's utterance has the same truthconditional content relative to both Anna and Bob's languages. Yet the dispute does not exhibit any conflict between Anna and Bob's beliefs about the facts that they take the utterance to be about. Because Anna believes that 'water' refers to vodka, she believes that her utterance of 'water has alcohol' is about whether vodka has alcohol; because Bob believes that 'water' refers to water, he believes that Anna's utterance is about whether water has alcohol. But, because whether vodka has alcohol has nothing to do with whether water has alcohol, Anna's beliefs about the facts that she believes her utterance to be about are entirely compatible with Bob's beliefs about the facts that he believes the utterance to be about. Thus, Anna and Bob's dispute is merely verbal: they disagree about whether Anna's utterance of 'water has alcohol' is true, but only because they disagree about what 'water' refers to.

Cases like these give us reason to adopt a characterization of non-merely-verbal disputes in terms of speaker's beliefs about their utterances' truth-conditional content, rather than in terms of those utterance's actual truth-conditional content. ${ }^{8}$ If by producing an assertoric utterance the speaker expresses a belief in the proposition she takes to be that utterance's truth-conditional content, and by disputing an utterance's truth the objector expresses disbelief in the proposition she takes to be that utterance's truth-conditional content, Disagreement in Content captures the idea that such disagreements really exhibit conflicts between the propositions the participants in a dispute express beliefs in. ${ }^{9}$ Yet, for all its virtues, the next section argues that Disagreement in Content leads to the troubling conclusion that nearly every dispute is merely verbal.

\section{The puzzle}

The puzzle arising from Disagreement in Content is this:

\footnotetext{
8 See Chalmers (2011) and Vermeulen (2018) for related points.

9 It is worth noting that Disagreement in Content is entirely compatible with externalism both about truthconditional content and about the content of people's beliefs. For example, according to the former, the truth-conditional content of a given utterance is not fully determined by the speaker's intrinsic properties. Clearly, there is no inconsistency in holding that kind of externalism together with Disagreement in Content, and the same goes for externalism about the content of beliefs.
} 
(P1) Disagreement in Content: A dispute between A and B over the truth of $\mathrm{U}$ is not merely verbal if and only if there is a proposition A and B both believe to be U's truth-conditional content.

(P2) Variance: Nearly every utterance is such that there is no proposition that more than one language user believes to be that utterance's truth-conditional content; therefore,

(C) Lost Disagreement: Nearly every utterance is such that any dispute over its truth is merely verbal.

Lost Disagreement follows straightforwardly from the premises, and I have argued that Disagreement in Content is an initially plausible account of what makes a dispute not merely verbal. Assuming that the proposition semantically expressed by an assertoric utterance is just that utterance's truth-conditional content, Variance states that, for nearly every utterance, there is no proposition that more than one language user takes that utterance to semantically express.

The case for Variance starts with the observation that, if two propositions $\mathrm{P}$ and $\mathrm{Q}$ have different modal profiles (i.e. there is some world in which one is true but the other isn't), then any given utterance has at most one of them as its truth-conditional content. ${ }^{10}$ Thus, for any given utterance, if two propositions have different modal profiles, any given language user with consistent beliefs will take at most one of those propositions to be that utterance's truth-conditional content. The problem is that, for nearly every assertoric utterance, there are enormously many propositions with different modal profiles which any language user could easily have believed to be that utterance's truth-conditional content, none of which is more natural or otherwise more eligible than the rest. Given the large number of equally eligible candidates, nearly every utterance is such that it would be extremely unlikely for there to be a proposition which more than one language user believes to be that utterance's truth-conditional content; absent further explanation, there is no such proposition. $^{11}$

Take for example gradable adjectives. One fruitful line of research in linguistics analyzes the positive form of gradable adjectives (e.g. 'tall', as opposed to 'taller') as a relation between the degree to which an object possesses the gradable property measured by the predicate and a contextually determined standard of comparison (See Cresswell (1977), Heim (2000), Kennedy and McNally (2005), Kennedy

\footnotetext{
10 This follows immediately from the definition of truth-conditional content in Sect. 2, above. To see this, take arbitrary propositions $\mathrm{P}$ and $\mathrm{Q}$ with different modal profiles and an arbitrary utterance U. Now, suppose for reductio that both $\mathrm{P}$ and $\mathrm{Q}$ are U's truth-conditional content. Because $\mathrm{P}$ and $\mathrm{Q}$ have different modal profiles, either there is a world $w$ in which $\mathrm{P}$ is true and $\mathrm{Q}$ is not, or there is a world $w^{\prime}$ in which $\mathrm{Q}$ is true and $\mathrm{P}$ is not. In the first case, since $\mathrm{P}$ is true in $w$, it follows from the definition of truth-conditional content that $\mathrm{U}$ is true in $w$ as well; but since $\mathrm{Q}$ is not true in $w$, it follows from the definition of truth-conditional content that $\mathrm{U}$ is not true in $w$. So $\mathrm{U}$ is both true and not true in $w$. Since the same goes, mutatis mutandis, for $w^{\prime}$, either way, we reach a contradiction. Thus, at most one of P and Q is U's truth-conditional content. Since P, Q and U were chosen arbitrarily, it follows that, for any given utterance, at most one of any two propositions with different modal profiles is that utterance's truth-conditional content.

11 See Abreu Zavaleta $(2018,2019)$ for further development. See Dorr and Hawthorne (2014) for a related argument to the effect that, if the propositions expressed by most sentences in ordinary language depend on microphysical facts, they depend very sensitively on those facts. See also Schiffer (1981) for a related argument to the effect that the content of an utterance can't include reference to specific modes of presentation, and Buchanan (2010) for a related argument against Gricean accounts of speaker meaning.
} 
(2007)). For example, the predicate 'tall' is taken to express the property of having a degree of tallness greater than or equal to a contextually determined standard of tallness; the predicate 'expensive' is taken to express the property of having a degree of cost greater than or equal to a contextually determined standard of cost; etc.

Now, suppose that Anna and Bob are debating Carla's height. Prompted by the question 'how tall is Carla?', Anna utters

(1) I'm not sure, but she is tall.

There are many contexts which Anna and John could easily have taken to be the one which Anna's utterance of 'she is tall' occupies, none of which is more natural or eligible than the rest, and all of which determine different standards of tallness. For instance, in one of those contexts Carla counts as "tall" just in case she is at least $1.8 \mathrm{~m}$ tall; in another she counts as "tall" just in case she is at least $1.81 \mathrm{~m}$ tall; etc. Given the large number of such contexts, it is very unlikely that Anna and John take Anna's utterance of 'she is tall' to occupy exactly the same one. Thus, it is very unlikely that there is a proposition Anna and Bob both take to be the truthconditional content of Anna's utterance of 'she is tall'. Most likely, if Anna and Bob in fact have beliefs about which context Anna's utterance occupies, Anna will believe that her utterance has the truth-conditional content that, say, Carla is tall at least to degree $\mathrm{x}$, but Bob will believe that the same utterance has the truth-conditional content that Carla is not tall at least to degree $\mathrm{x}^{*}$, where $\mathrm{x} \neq \mathrm{x}^{*}$. Thus, if Bob disputes Anna's utterance - e.g. by saying 'no, she's not' - it would be extremely unlikely for their dispute to count as non-merely-verbal by the lights of Disagreement in Content.

Considerations of this kind hold not just for gradable adjectives, but for nearly every context-dependent expression, including location adverbs like 'here' or 'there'. For nearly every utterance involving a context-dependent expression, there are many equally eligible contexts any language user could easily have taken the utterance to occupy, all of which determine different values for the parameters on which the utterance's truth-conditional content depends - and, accordingly, all of which determine different truth-conditional contents for that utterance.

The present considerations apply to context-independent expressions as well. For example, if the application of a word like 'quesadilla' depends on how much cheese something has, it is extremely unlikely for any two language users to agree on the truth-conditional content of an utterance of 'Carla ate a quesadilla'. After all, there are a huge number of equally eligible cutoff points along a scale of quantity of cheese which those two language users could easily have taken to be determined by the actual meaning of the word 'quesadilla'. Given the huge number of such equally eligible cutoff points, it would be extremely unlikely for any two language users to agree on which of them is the one determined by the meaning of the word 'quesadilla'.

The foregoing kind of observations hold for (but are not limited to) utterances involving predicates and relations whose application depends on the properties an object (or tuple of objects) has along one or more sufficiently fine-grained dimen- 
sions. ${ }^{12}$ What I surmise is that nearly every utterance will involve a predicate or relation of that kind. This is the main point in favor of Variance. ${ }^{13}$

Sections 4 and 5 discuss seemingly natural solutions to the puzzle and argue that they are not successful, and Sect. 6 outlines my preferred solution. Before continuing to that discussion, it is worth emphasizing what makes Lost Disagreement problematic. To this end, consider two cases.

In the first case, Anna and Bob are reporters at Sport Illustrated. When discussing who to include in the list of the fifty greatest athletes of the 20th century, Anna utters 'Secretariat was an athlete', thinking that Secretariat should be included in the list because he trained and competed in races. Thinking that Bob shouldn't be included in the list because he wasn't human, Bob replies 'no, he wasn't'. Anna and Bob's dispute is settled once they discover they understood the word 'athlete' in different ways. ${ }^{14}$

In the second case, Bob wants to know if Carla will reach a certain shelf, and asks Anna how tall Carla is. Anna, who has a recent photograph of Carla nearby and sees that Carla is about $2 \mathrm{~m}$ tall, replies 'she's tall'. Bob, who still thinks of Carla as the girl he met when she was 10 years old, replies 'no, she's not'. Anna and Bob's dispute is settled when he sees Carla's recent photograph and realizes that Carla is about $2 \mathrm{~m}$ tall; at that point, he concedes that Anna was right.

The case for Lost Disagreement is problematic not because it entails that nearly every dispute is like Anna and Bob's dispute about Secretariat-the case for Lost Disagreement has no such entailment, and that dispute does seem to be merely verbalbut because it entails that even seemingly normal disputes like Anna and Bob's dispute

\footnotetext{
12 Continuous dimensions are the prime example of a fine-grained dimension, but even dimensions with a finite number of points can satisfy this requirement. For instance, even if the application of $\mathrm{F}$ depends on an object's properties along a dimension with only 10,000 points, the present argument would go through. All the argument requires is that there are enough points along those dimensions for there to be a large number of very similar and equally eligible properties (all with a plausible claim to be the one expressed by F), each corresponding to slightly different cutoff points along those dimensions. Predicates whose application depends on an object's properties along continuous dimensions (e.g. gradable adjectives) are prime examples of this kind of predicate, but they are not the only such examples. As the discussion so far illustrates, 'quesadilla' and gradable adjectives in general are examples of the kind of predicate I refer to in the main text.

13 Plausibly, appealing to vague propositions will not take us very far in resisting Variance. There is no generally accepted treatment of vague propositions, but it is entirely compatible with the case for Variance that in the schema $A$ believes that $U$ has the truth-conditional content $P, \mathrm{P}$ be a vague proposition. All the case for Variance requires is that for nearly every utterance $U$ there are many equally natural vague truth-conditional contents any language user could easily have believed that utterance to have. Given this condition, it would be extremely unlikely for there to be a vague proposition which more than one language user takes to be U's truth-conditional content. Appealing to vagueness in the identity conditions of vague truth-conditional contents will not take us very far in solving the puzzle. Strictly speaking, all we need in order to generate a version of the puzzle is that, for nearly every utterances, there is a large enough number of equally natural (or otherwise eligible) yet not definitely identical truth-conditional contents any language user could easily have believed each of those utterances to have. Given the huge number of not-definitelyidentical truth-conditional content candidates each of those utterances has, it would be extremely unlikely for any two language users to definitely have the same beliefs about those utterances' truth-conditional contents. If this is true, then nearly every utterance is such that no dispute over its truth is definitely not merely verbal.

14 Thanks to an anonymous reviewer for bringing this case to my attention. My version of the case is based on an example by Ludlow, who thinks that the dispute is merely verbal: "Clearly this is a dispute about what should be in the extension of "thlete"' (Ludlow 2014, p. 78).
} 
about Carla's height are merely verbal. Given the truth of Variance, it is extremely likely that there is no proposition which both Anna and Bob take to be the truthconditional content of Anna's utterance of 'she's tall', in which case Disagreement in Content entails that their dispute about that utterance is merely verbal. An adequate solution to the puzzle should avoid this result—i.e. it should predict, of everyday, seemingly non-verbal disputes like Anna and Bob's dispute about Carla's height, that they are not merely verbal.

\section{Rejecting disagreement in content}

Non-merely-verbal disputes are those that exhibit a conflict between the disputants' beliefs about the facts they take the disputed utterance to be about. One way of rejecting Lost Disagreement is by rejecting that Disagreement in Content adequately captures that kind of conflict. This section considers some natural replacements for Disagreement in Content and argues that they do not adequately solve the puzzle.

\subsection{Factual conflicts}

Perhaps Disagreement in Content is too restrictive to capture what it is for the participants in a dispute to express conflicting beliefs about the facts they take the utterance under dispute to be about. For, in general, a belief in $\mathrm{P}$ and a belief in $\mathrm{Q}$ are in conflict just in case they cannot both be true. Yet this doesn't require that $\mathrm{P}$ and $\mathrm{Q}$ are each other's negations. For instance, a belief that Bob is in the bathroom and a belief that there is no one in the bathroom cannot both be true, yet the proposition that Bob is in the bathroom is not necessarily equivalent to the negation of the proposition that there is no one in the bathroom.

Given this observation, one may think that the following definition better captures the kind of conflict we are after:

Factual conflicts: If A utters U, and B disputes the truth of U, A and B's dispute over the truth of $U$ is not merely verbal if and only if, where $P$ is the proposition A believes to be U's truth-conditional content, and Q is the proposition $\mathrm{B}$ believes to be U's truth-conditional content, $\mathrm{P}$ and $\neg$ Q cannot both be true. ${ }^{15}$

For example, suppose that Anna utters 'Carla is tall' and believes that her utterance's truth-conditional content is the proposition that Carla is at least $1.8 \mathrm{~m}$ tall. Bob disputes the truth of Anna's utterance, which he takes to have the truth-conditional content that Carla is at least $1.6 \mathrm{~m}$ tall. Then, according to Factual Conflicts, Anna and Bob's dispute is not merely verbal, since the proposition that Carla is at least $1.8 \mathrm{~m}$ tall and the proposition that it's not the case that Carla is at least $1.6 \mathrm{~m}$ tall cannot both be true.

15 Sider (2006, p. 76) uses a similar characterization of non-verbal disputes, albeit in terms of what an utterance means for the different parties of a dispute. See Vermeulen (2018) for a similar characterization, albeit in terms of speaker meaning. Egan (2010, p. 255) defines genuine disagreements in a similar way. The differences between their characterizations and Factual Conflicts do not matter for present purposes. 
Given this characterization of non-merely-verbal disputes, it is compatible with the truth of Variance that many ordinary disputes are not merely verbal. For example, consider a case in which Anna utters

\section{(2) Carla is tall}

and Bob replies 'that's not true'. It would be very unlikely for there to be a degree of tallness such that Anna and Bob both believe that the truth-conditional content of Anna's utterance is the proposition that Carla is tall to at least that degree. Most likely, if Anna and Bob have any beliefs at all about the context Anna's utterance occupies, Anna will believe that her utterance has the truth-conditional content that, say, Carla is tall to degree $\mathrm{x}$ or higher, but Bob will believe that his utterance has the truth-conditional content that Anna is not tall to degree $\mathrm{x}^{*}$ or higher, where $\mathrm{x} \neq \mathrm{x}^{*}$.

By itself, the fact that $\mathrm{x}$ is different from $\mathrm{x} *$ does not entail that the proposition that Carla is tall at least to degree $\mathrm{x}$ is compatible with the proposition that Carla is not tall at least to degree $\mathrm{x}^{*}$. It may be well be that being tall at least to degree $\mathrm{x}$ entails being tall at least to degree $\mathrm{x}^{*}$, in which case the proposition that Carla is tall at least to degree $\mathrm{x}$ will be incompatible with the proposition that Carla is not tall at least to degree $\mathrm{x}^{*}$. This will be the case if, for example, $\mathrm{x}=1.81 \mathrm{~m}$ and $\mathrm{x}^{*}=1.8 \mathrm{~m}$. In that case, by uttering (2), Anna will have expressed her belief that Carla is at least $1.81 \mathrm{~m}$ tall. On the other hand, by disputing the truth of Anna's utterance, Bob will have expressed his belief that it is not the case that Carla is at least $1.8 \mathrm{~m}$ tall. According to Factual Conflicts, since those two beliefs cannot both be true, Anna and Bob's dispute is not merely verbal in the present scenario.

The problem is that, given the truth of Variance, it is still relatively unlikely for this kind of happy scenario to obtain (though, admittedly, more likely than the scenario in which Anna and Bob's dispute exhibits a full disagreement in content). For example, Anna could easily have believed her utterance to have the truth-conditional content that Carla is at least $1.8 \mathrm{~m}$ tall, and Bob could easily have believed the same utterance to have the truth-conditional content that Carla is at least $1.81 \mathrm{~m}$ tall. Given Factual Conflicts, since the proposition that Carla is at least $1.8 \mathrm{~m}$ tall is entirely compatible with the proposition that it is not the case that Carla is at least $1.81 \mathrm{~m}$ tall (e.g. they can both be true if Carla is $1.8 \mathrm{~m}$ tall), Anna and Bob's dispute would have been merely verbal in this case.

More generally, given Factual Conflicts, Anna and Bob's dispute over the truth of Anna's utterance is not merely verbal only if the standard of tallness Anna takes to determine her utterance's truth-conditional content is greater than or equal to the standard of tallness Bob takes to determine the same utterance's truth-conditional content. But this condition could have failed to obtain relatively easily. To focus on a finite case, suppose that there are three standards of tallness Anna and Bob could easily have taken to determine the truth-conditional content of Anna's utterance: $a<b<c$. Suppose also that these three standards of tallness are equally easy to latch on to; i.e. the chance that Anna chooses $a$ as the standard relevant to her utterance is just the same as the chance she took $b$ and the chance she took $c$ (i.e. $\frac{1}{3}$ ), and the same goes for Bob. Then there would be a $\frac{1}{3}$ chance that Bob had chosen a standard of tallness 
greater than the standard Anna chose. ${ }^{16}$ In this way, it would be relatively likely for Bob to have chosen a standard of tallness greater than the one Anna chose, in which case it will be relatively likely for Anna and Bob's dispute to be merely verbal.

Even more generally, if there are $n$-many strictly ordered standards of tallness Anna and Bob could easily have taken to determine the truth-conditional contents of Anna's utterances, the chance that Anna's standard is greater than or equal to Bob's (assuming that all of those standards are equally likely to be picked) is

$$
\frac{1+2+\cdots+n}{n^{2}}
$$

where $1+2+\cdots+n$ is the number of ways in which the standard of tallness Anna chooses is greater than or equal to the standard of tallness Bob chooses, and $n^{2}$ is the number of possible combinations of Anna and Bob's choices. ${ }^{17}$ As the value of $n$ increases, the chance that Anna's standard is greater than or equal to Bob's decreases, approaching $\frac{1}{2}$. Thus, given Factual Conflicts and a sufficiently high number of standards of tallness Anna and Bob could easily have picked, it will be relatively likely for Anna and Bob's dispute to be merely verbal-consider, for instance, that when $n=10$, the chance that Anna's standard is greater than or equal to Bob's is 0.55.

The present considerations give rise to two problems for the present view. The first is that, in conjunction with Variance, Factual Conflicts still makes it relatively likely for a dispute to be merely verbal — though, admittedly, less likely than if we adopt Disagreement in Content. This is problematic in itself, since the arguments above show that, with respect to a very large class of utterances, it is practically a matter of chance whether a dispute over a given utterance in that class is merely verbal.

The second problem concerns our knowledge of whether a given dispute is merely verbal. Typically, our default assumption about a dispute over an utterance's truth is that it is not merely verbal, though we may be prepared to revise this assumption if the dispute deviates from what we consider a normal dispute. In this way, our basis for judging that two people engage in a non-verbal dispute is usually the very fact that they have a dispute over an utterance's truth, plus the fact that the dispute follows a seemingly normal course. But, if the foregoing observations and Factual Conflicts are both true, we could not come to know that two people are engaging in a dispute that is not merely verbal just on the basis of the fact that the dispute follows a seemingly normal course-since, given the present observations, many disputes that

\footnotetext{
16 Provided that $a, b, c$ are all the standards of taste Anna and Bob could easily have chosen, there are $3^{2}$ possible ways for Anna and Bob to have chosen such standards: i.e. Anna and Bob both choose $c$, Anna chooses $c$ and Bob chooses $b$, etc. Among these possibilities, there are six in which Anna chooses a standard of tallness at least as high as Bob's: Anna chooses $c$ and Bob chooses $c$, Anna chooses $c$ and Bob chooses $b$, etc. Thus, there is a $\frac{6}{9}=\frac{2}{3}$ chance that the standard Anna chooses is at least as high as Bob's, and a corresponding chance of $\frac{1}{3}$ that it is not.

17 To see that the number of ways in which Anna's standard of tallness is greater than or equal to Bob's is $1+2+\cdots+n$, consider the following. Let $s_{1}<s_{2}<\cdots<s_{n}$ be the standards of tallness Anna and Bob could easily have chosen. If Anna chooses $s_{n}$, there are n-many ways for Bob to choose a standard lower than or equal to Anna's: $s_{n}, s_{n-1}, \ldots, s_{1}$. If Anna chooses $s_{n-1}$, there are $n-1$ ways for Bob to choose a standard lower than or equal to Anna's: $s_{n-1}, s_{n-2}, \ldots, s_{1}$, and so on. Which is to say that there are $n+(n-1)+\cdots+1$ ways for Bob to choose a standard lower than or equal to Anna's.
} 
follow seemingly normal courses will still count as merely verbal. The question thus arises whether and how we can know, of a non-merely-verbal dispute, that it is not merely verbal. Furthermore, to the extent that it is irrational to seriously engage in disputes we don't know not to be merely verbal, nearly every utterance is such that it would be irrational to seriously engage in a dispute over its truth.

Before proceeding, I want to make two important observations about the present line of reasoning. The first is that the present argument focuses on the case of gradable adjectives and relies on special (though widely accepted) assumptions about their semantics. However, the same considerations apply whenever the plausible truthconditional content candidates for a given utterance can be strictly ordered by logical strength. For example, such considerations apply to utterances whose plausible truthconditional content candidates include propositions like $A$ weighs at least $5 \mathrm{~kg},{ }^{18} \mathrm{~A}$ weighs at least $5.1 \mathrm{~kg}$, A weighs at least $5.5 \mathrm{~kg}$, and so on, which can be strictly ordered by the weight they attribute to object A. They similarly apply to utterances whose truth-conditional content candidates include the proposition that $\mathrm{A}$ is longer than many $\mathrm{Fs}$, the proposition that $\mathrm{A}$ is longer than very many Fs, the proposition that $\mathrm{A}$ is longer than most Fs, the proposition that $\mathrm{A}$ is longer than nearly every $\mathrm{F}$, and so on.

This brings us to the second observation, which is that the present argument does not apply to disputes about all the utterances that instantiate Variance. For example, suppose Anna and Bob debate where Carla was standing when she threw the ball at a basketball game, and Anna utters:

(3) Carla was standing here.

Suppose further that Anna and Bob both believe that 'here' as it was used in Anna's utterance refers to the location where Anna is standing. There are many spatial regions Anna and Bob could easily have believed Anna to be standing on; accordingly, there are many spatial regions Anna and Bob could easily have taken 'here' as used by Anna to refer to. For instance, those regions could be more or less as depicted in Fig. 1-where each circle represents a spatial location Anna and Bob could easily have believed 'here' to refer to. As the figure illustrates, all of those regions overlap to some extent, and some of those regions will be included in others, but not every region will include or be included in another. In this case, we can't strictly order the propositions Anna and Bob could easily have taken to be the truth-conditional content of Anna's utterance by logical strength, so we can't apply the argument we used in the case of gradable adjectives.

Note, however, that in this kind of scenario a dispute over the truth of Anna's utterance of (3) would count as non-merely-verbal (given Factual Conflicts) only if the location Bob takes to be the referent of 'here' as it occurs in Anna's utterance is included in the location Anna takes to be the referent of 'here'. However, it is still unlikely that such a thing would happen-i.e. it is unlikely that the location Anna takes to be the referent of 'here' includes the location Bob takes to be the referent of 'here'. And even if it does happen, the question arises if and how we could know that it does happen.

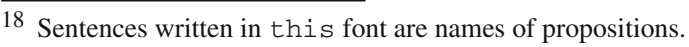


Fig. 1 Some spatial locations

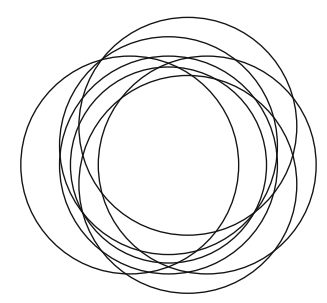

To summarize, we have seen that if Variance and Factual Conflicts are both true, typical disputes are still relatively likely to be merely verbal. Furthermore, the relative likelihood that a dispute is merely verbal raises the question of whether and how we can know, of a dispute that is not merely verbal, that it is not merely verbal. This is just as problematic: typically, we engage in disputes on the assumption that we are not merely talking past each other, but if we don't know that our dispute is not merely verbal, it would be difficult to justify this attitude.

\subsection{Appealing to multiplicity}

\subsubsection{Cloudy conflicts}

Von Fintel and Gillies (2011) have argued that in certain cases the context underspecifies the parameters on which the semantic content of an utterance depends. ${ }^{19}$ In those cases, there are many propositions that the utterance puts into play, each of which would be the utterance's semantic content under a different way of resolving contextual underspecification. For example, the context in which Anna uttered (2) may fail to specify a single standard of tallness on which the truth of Anna's utterance depends; instead, there will be many standards of tallness which could plausibly resolve the contextual underspecification, such as the standard on which Carla counts as "tall" iff she is at least $1.8 \mathrm{~m}$ tall, the standard on which Carla counts as "tall" iff she is at least $1.81 \mathrm{~m}$ tall, and so on. Thus, there will be many propositions that Anna's utterance puts into play, namely, the proposition that Carla is at least $1.8 \mathrm{~m}$ tall, the proposition that Carla is at least $1.81 \mathrm{~m}$ tall, and so on. The same goes, mutatis mutandis, for cases of semantic rather than contextual underspecification.

Adapting von Fintel and Gillies' proposal to the present discussion, the following norms guide assertion and rejection in cases of underspecification (cf. von Fintel and Gillies 2011, pp. 120, 121):

Assert: In order to produce utterance U, A must believe one of the propositions that she believes that $\mathrm{U}$ puts into play.

Reject: $B$ can reject utterance $U$ if the strongest proposition that $B$ believes that $U$ puts into play and B reasonably has an opinion about is such that B believes that that proposition is false.

\footnotetext{
19 See Beddor and Egan (2018), section 7.2, for a different version that uses the notion of a question under discussion.ferences between that implementation and the present one do not matter for present purposes.
} 
For example, if Anna believes that her utterance of (2) puts in play the proposition that Carla is at least $1.8 \mathrm{~m}$ tall and the proposition that Carla is at least $1.81 \mathrm{~m}$ tall, she must have believed at least one of them if her utterance is to be warranted. And if Bob believes that those two propositions are the ones that (2) puts in play, he can reject Anna's utterance if the strongest proposition he reasonably has an opinion on is such that Bob believes it to be false.

Given the present norms for assertion and rejection, one could attempt to capture the kind of conflict in beliefs that characterizes non-merely-verbal disputes as follows:

Cloudy conflicts: If A utters $\mathrm{U}$, and $\mathrm{B}$ disputes the truth of $\mathrm{U}$, then $\mathrm{A}$ and $\mathrm{B}$ 's dispute over the truth of $U$ is not merely verbal if and only if there are propositions $\mathrm{P}$ and $\mathrm{Q}$ such that:

(i) A believes that $\mathrm{P}$ is true, and that $\mathrm{U}$ puts $\mathrm{P}$ in play.

(ii) $\mathrm{B}$ believes that $\mathrm{Q}$ is false, and $\mathrm{Q}$ is the strongest proposition that Bob believes $\mathrm{U}$ to put in play and B reasonably has an opinion about.

(iii) It can't be the case that $\mathrm{P}$ is true while $\mathrm{Q}$ is false.

According to Cloudy Conflicts, if Anna believes that her utterance of (2) puts in play the proposition that Carla is at least $1.81 \mathrm{~m}$ tall and believes that proposition, and the strongest proposition about which Bob reasonably has an opinion and which Bob takes (2) to put in play is the proposition that Carla is at least $1.8 \mathrm{~m}$ tall, then Anna and Bob's dispute is not merely verbal.

Cloudy Conflicts is problematic for roughly the same reasons as Factual Conflicts. Given Cloudy Conflicts, Anna and Bob's dispute is not merely verbal only if there is a proposition on the basis of which Anna utters (2) which is logically at least as strong as the strongest proposition that Bob takes Anna's utterance to put in play and about which he can reasonably have an opinion, yet this condition could easily have failed to obtain. For example, suppose that Anna uttered (2) because she believes that Carla is at least $1.8 \mathrm{~m}$ tall. It could easily have been that the strongest proposition about which Bob can reasonably have an opinion and which Bob believes to be put in play by Anna's utterance is stronger than the proposition that Carla is at least $1.8 \mathrm{~m}$ tall; for example, that proposition could easily have been the proposition that Carla is at least $1.81 \mathrm{~m}$ tall. But, since it can be the case both that Carla is at least $1.8 \mathrm{~m}$ tall and that it's not the case that Carla is at least $1.81 \mathrm{~m}$ tall (e.g. if Carla is $1.8 \mathrm{~m}$ tall), Cloudy Conflicts predicts that Anna and Bob's dispute is not merely verbal.

More generally, for reasons discussed above (Sect. 4.1, p. 11), it is relatively unlikely that the strongest proposition on the basis of which Anna utters (2) is stronger than the strongest proposition that Bob rejects and takes to be put in play by Anna's utterance. Accordingly, it is unlikely that Anna and Bob's dispute satisfies the condition imposed by Cloudy Conflicts. For example, if there are ten propositions which Anna and Bob both believe to be put in play by Anna's utterance, the chance that their dispute satisfies the condition imposed by Cloudy Conflicts is 0.55 (see above, p. 11). ${ }^{20}$ This is problematic in and of itself, but, as I argued in Sect. 4.1, it is also problematic because

\footnotetext{
20 I am assuming that all of those propositions are equally likely to be the strongest proposition on the basis of which Anna uttered (2), and equally likely to be the strongest proposition which Bob rejects and takes to be put at play by Anna's utterance.
} 
it raises the question of whether and how we can know, of non-merely-verbal disputes, that they are not merely verbal.

Note that it doesn't help to weaken the norm for rejection so that it is on a par with the norm of assertion. According to that weakening, a hearer can reject an utterance if there is some proposition which she believes to be put in play by the utterance and which she believes to be false. Given this weakening, we could reformulate Cloudy Conflicts as follows:

Cloudy Conflicts*: If A utters U, and B disputes the truth of U, then A and B's dispute over the truth of $U$ is not merely verbal if and only if there are propositions $\mathrm{P}$ and $\mathrm{Q}$ such that:

(i) A believes that $\mathrm{P}$ is true, and that $\mathrm{U}$ puts $\mathrm{P}$ in play.

(ii) $\mathrm{B}$ believes that $\mathrm{Q}$ is false, and that $\mathrm{U}$ puts $\mathrm{Q}$ in play.

(iii) It can't be the case that $P$ is true while $Q$ is false.

Take once more Anna and Bob's dispute over the truth of Anna's utterance of (2). The condition in Cloudy Conflicts* is satisfied only if the strongest proposition on the basis of which Anna utters (2) is stronger than the weakest proposition which Bob believes to be put in play by (2) and which Bob believes to be false. But, assuming that all the propositions that both Anna and Bob take to be put in play by Anna's utterance all have equal chances of being the strongest of those propositions which Anna believes, and all have equal chances of being the weakest of those propositions which Bob rejects, then, as the number of the propositions that both Anna and Bob take to be put in play increases, the chance that the condition in Cloudy Conflicts* is satisfied decreases, approaching 0.5 (see p. 11, above). A further objection to both Cloudy Conflicts and Cloudy Conflicts* is that, in cases in which the participants in a dispute each take the utterance that the dispute is about to put exactly one proposition in play, both Cloudy Conflicts and Cloudy Conflicts* collapse into Factual Conflicts, with all the problems that this entails.

\subsubsection{Multiple rejection}

The idea that there are multiple propositions that an utterance "puts in play" may be appealing even if one does not accept von Fintel and Gillies' particular implementation. For it may seem appealing to think that, in a normal conversation, the hearer will think that there are many different propositions which the speaker could reasonably have intended to communicate through a single utterance. ${ }^{21}$ And, since the hearer does not know which of those propositions the speaker actually tried to communicate, she will only dispute the truth of the utterance if she believes that all the propositions which the speaker might have tried to communicate are false.

According to this view, when Bob hears Anna's utterance, he might not be sure of exactly which proposition Anna tried to communicate. For all Bob knows, Anna could have reasonably tried to communicate the proposition that Carla is at least $1.8 \mathrm{~m}$ tall, the proposition that Carla is at least $1.81 \mathrm{~m}$ tall, and so on. Because Bob doesn't know which of those propositions Anna was actually trying to communicate, he will be

21 Thanks to an anonymous reviewer for this way of putting the idea. 
careful to reject Anna's utterance only if he thinks that all of them are false. If speakers who reject utterances are typically like Bob, we can generalize these observations into the following proposal:

Multiple Rejection: If A utters U, and B disputes the truth of U, A and B's dispute over the truth of $U$ is not merely verbal if and only if B believes, of every proposition which she believes that A could reasonably have tried to communicate through $\mathrm{U}$, that that proposition is false.

I am skeptical that Multiple Rejection captures the idea that non-merely-verbal disputes exhibit conflicts between the disputants' beliefs about the facts that they take the utterance under dispute to be about; this because not every dispute that satisfies Multiple Rejection will exhibit such conflict. Suppose that Anna thinks that she can reasonably intend to communicate the proposition that Carla is at least $1.79 \mathrm{~m}$ tall through her utterance of (2), and that, as a matter of fact, what Anna intends to communicate through her utterance of (2) is the proposition that Carla is at least $1.79 \mathrm{~m}$ tall. Suppose, furthermore, that that proposition is not one which Bob believes that Anna could have reasonably attempted to communicate; this would be the case if, for example, the weakest standard for the application of "tall" that Bob takes to be reasonable in the context of Anna's utterance is one in which a person counts as tall only if she is at least $1.8 \mathrm{~m}$ tall. In that case, if Bob believes that it is not the case that Carla is at least $1.8 \mathrm{~m}$ tall, Multiple Rejection predicts that Anna and Bob's dispute is not merely verbal, yet the proposition that Anna intended to communicate through her utterance is fully compatible with Bob's beliefs about Carla's height. Hence, Multiple Rejection doesn't capture sufficient conditions for the existence of conflicts between the disputants' beliefs about the facts they take the utterance under dispute to be about.

The counterexample is not idle: for nearly every utterance, there are many equally eligible, albeit slightly different, sets of propositions which any language user could easily have been taken to be the set of all and only the propositions which the speaker could have reasonably intended to communicate through that utterance. For instance, in the case of Anna's utterance of (2), some of those sets may include the proposition that Carla is at least $1.79 \mathrm{~m}$ tall but not the proposition that Carla is at least $1.9 \mathrm{~m}$ tall; others may include the latter but not the former, and so on. Given the huge number of such sets, nearly every utterance is such that it would be extremely unlikely for there to be one which more than one language user believes to be the set of all and only the propositions which the speaker could have reasonably intended to communicate through that utterance. This being so, there is plenty of room for actual counterexamples to the sufficiency of Multiple Rejection to arise.

I am also skeptical that Multiple Rejection captures a necessary condition for disputes not to be merely verbal. Suppose that the propositions that Carla is at least $1.8 \mathrm{~m}$ tall and that Carla is at least $1.85 \mathrm{~m}$ tall are among the propositions which Bob thinks that Anna could reasonably have intended to communicate through her utterance of (2). Bob believes that it is not the case that Carla is at least $1.85 \mathrm{~m}$ tall, but, for all he believes, Carla might be at least $1.81 \mathrm{~m}$ tall. Furthermore, though Bob believes that there are many other propositions which Anna could reasonably have intended to communicate by uttering (2), he believes that what Anna in fact intended to communicate is that Carla is at least $1.85 \mathrm{~m}$ tall, so he rejects Anna's utterance. As it 
happens, unlikely as it might be, what Anna intended to communicate really was the proposition that Carla is at least $1.85 \mathrm{~m}$ tall. This is a case in which Anna and Bob have conflicting beliefs about the facts they take Anna's utterance to be about: Anna believes that Carla is at least $1.85 \mathrm{~m}$ tall, while Bob believes that that is not the case. Yet, according to Multiple Rejection, Anna and Bob's dispute is merely verbal, since Bob doesn't reject all the propositions which he thinks Anna could reasonably have attempted to communicate.

\subsection{Pseudo-conflicts}

The last replacement for Disagreement in Content that I will consider is the following:

Pseudo-conflicts: If A utters U, and B disputes the truth of U, A and B's dispute over the truth of $U$ is not merely verbal if and only if, where $P$ is the proposition A believes to be U's truth-conditional content, and Q is the proposition B takes to be U's truth-conditional content, $\mathrm{P}$ and $\mathrm{Q}$ are similar enough.

For example, suppose that Anna believes that the truth-conditional content of her utterance of (2) is the proposition that Carla is at least $1.8 \mathrm{~m}$ tall, and Bob believes that that utterance's truth-conditional content is the proposition that Carla is at least $1.81 \mathrm{~m}$ tall. Intuitively, these two propositions are very similar in that they attribute to Carla very similar degrees of tallness. Given this scenario, if Bob disputes the truth of Anna's utterance, the resulting dispute will be merely verbal according to Factual Conflicts (since it may be true that Carla is at least $1.8 \mathrm{~m}$ tall, but not at least $1.81 \mathrm{~m}$ tall). However, according to the present definition, that similarity between the propositions which Anna and Bob (respectively) believe to be that utterance's truth-conditional content suffices for their dispute not to be merely verbal.

If Pseudo-conflicts is true, Variance is entirely compatible with the claim that typical disputes are not merely verbal. For, by assumption, the truth-conditional content candidates ordinary language users could easily have believed a given utterance to have are extremely similar to one another, which means that typical disputes could very easily satisfy the condition imposed by Pseudo-conflicts. For this reason, some people may think that Pseudo-conflicts is a promising replacement for Disagreement in Content.

There are two problems with the present solution to the puzzle. The first is one of underdevelopment: in order for the present strategy to count as a successful response to the present puzzle, we need to flesh out similarity between propositions. Yet it is not obvious when two propositions count as similar for the purposes of disagreement. For instance, consider the following propositions:

(4) Carla is at least $1.8 \mathrm{~m}$ tall

(5) Carla is at least $1.81 \mathrm{~m}$ tall

(6) Carla is exactly $1.8 \mathrm{~m}$ tall or at least $1.81 \mathrm{~m}$ tall

(7) Carla is at least $1.81 \mathrm{~m}$ tall or weighs exactly $40 \mathrm{~kg}$

Presumably, these four propositions all have very similar modal profiles (i.e. they are true in roughly the same possible worlds), yet it is not clear that they are all similar 
to the degree required by Pseudo-conflicts. Though this underdevelopment is not in itself a reason to reject the present approach, it does show that much more work needs to be done in order to consider it a satisfying solution.

The second, more pressing problem, is that if similarity between propositions depends solely on those propositions' intrinsic properties, then Pseudo-conflicts fails to capture the idea that non-merely-verbal disputes over an utterance's truth exhibit conflicts between the disputants' beliefs about the facts they take that utterance to be about. For instance, suppose Anna utters 'Carla is tall' and Bob replies 'no, she's not'. As it happens, Anna believes that her utterance's truth-conditional content is c and Bob believes that the same utterance's truth-conditional content is (5). It is entirely possible that (4) is true and (5) is false, and it is even possible that Anna knows that (4) is true and Bob knows that (5) is false- this will be the case if, for example, Carla is between 1.8 and $1.81 \mathrm{~m}$ tall, and Anna and Bob both know this. But if this is possible, it is not clear in what sense Anna's belief that (4) is true would conflict with Bob's belief that (5) is false. Absent further elaboration on how those beliefs are in conflict, Pseudo-Conflicts fails to capture the idea that non-merely-verbal disputes over the truth of a given utterance exhibit conflicts between the disputants' beliefs about the facts they take that utterance to be about.

More generally, if (i) $R$ is a relation between propositions other than logical dependence or logical incompatibility, and (ii) $R$ holds solely in virtue of the intrinsic properties of its relata, the present objection holds for any definition resulting from substituting $R$ for similarity between propositions in Pseudo-conflicts. For if $R$ is such a relation, and $\mathrm{P}$ and $\mathrm{Q}$ are contingent propositions, then it is possible that $R$ holds of $\mathrm{P}$ and $\mathrm{Q}$, that $\mathrm{P}$ is true, and that $\mathrm{Q}$ is false (or the other way around). And, if this is so, it is unclear in what sense the version of Pseudo-conflicts appealing to $R$ captures the idea that non-merely-verbal disputes about an utterance's truth exhibit a conflict between the disputants' beliefs about the facts they take that utterance to be about. Thus, if we are to capture the kind of conflict that characterizes non-merely-verbal disputes in terms of a relationship between propositions (other than logical incompatibility), that relation should not depend only on the intrinsic properties of its relata.

Let me summarize the discussion so far. I have argued that seemingly natural replacements for Disagreement in Content do not adequately solve the puzzle. On the one hand, given the case for Variance, Factual Conflicts and Cloudy Conflicts still make it relatively unlikely for a dispute over the truth of an utterance not to be merely verbal; that unlikeliness makes it difficult to see how we could know of a dispute which in fact is not merely verbal, that it is not merely verbal. On the other, Multiple rejection and Pseudo-conflicts fail to capture sufficient or necessary conditions for when there is a conflict between the disputants' beliefs about the facts that they take the utterance under dispute to be about. ${ }^{22}$

\footnotetext{
22 The following proposal might also be worth considering. Perhaps influenced by Barker (2002), contextualists like Sundell (2011), Khoo (2020), and Khoo and Knobe (2016) have recently claimed that in disputing the truth of an utterance one partly disputes certain ways of using some of the terms used in the utterance under dispute.tance, if Anna utters 'Carla is tall' and Bob utters 'no, she isn't', part of what Bob is objecting to is Anna's use of the word 'tall' in a way that applies to Carla. However, this need not reflect a conflict between Anna and Bob's beliefs about Anna's height; Anna and Bob may both believe that Carla is, say, $1.7 \mathrm{~m}$ tall, and their disagreement is only over whether to adopt a standard of tallness that would
} 
This is not to say that rejecting Disagreement in Content is a bad strategy. In fact, I believe that any plausible solution to the puzzle must reject Disagreement in Content, but the discussion suggests that we need a somewhat more radical departure from standard accounts of non-verbal disputes. Before outlining a more adequate replacement, I consider the option of rejecting Variance.

\section{Rejecting variance}

The case for Variance raises a challenge: to explain why people who engage in disputes over the truth of an utterance would agree on what that utterance's truth-conditional content is despite the huge number of equally natural and plausible truth-conditional content candidates they could each easily have taken the utterance to have. To get a better idea of what this challenge amounts to, suppose there are two normal mercury thermometers submerged in the same liquid, and that that liquid has a temperature of around fifty degrees. There is a large number of readings each of the two thermometers could easily have produced, corresponding to the points in the line between (say) the marks signaling forty-nine and fifty-one degrees. Given the large number of extremely similar candidate readings, even small differences in calibration, the exact temperature of the liquid surrounding each thermometer, the amount of mercury in each thermometer, and so on, are likely to produce a difference in the exact readings the thermometers produce. Thus, though the two thermometers may give very similar readings, they are very unlikely to produce the exact same one (See Abreu Zavaleta 2019).

The case for Variance assumes that any two people's beliefs about an utterance's truth-conditional content are as imperfectly correlated as the readings of the two thermometers from the example. Given the large number of plausible and extremely similar truth-conditional contents any two language users could easily have believed an utterance to have, even small differences in those people's evidence, their attunement to the evidence, and the information they deem relevant to determining the utterance's truth-conditional content, among other factors, are likely to produce differences in the exact truth-conditional content they believe a given utterance to have. The challenge is to explain why, and how, ordinary disputants would typically agree about the truth-conditional content of the disputed utterances despite these considerations.

I am skeptical that this challenge can be answered. In order to answer the challenge, one would have to argue either (a) that certain propositions among the extremely similar and seemingly equally good candidates are especially easy to latch on to, such that it would be likely for people who engage in disputes to agree on which proposition is the truth-conditional content of the utterance the dispute is about; or (b) that people's beliefs about what truth-conditional content an utterance has are so closely correlated

Footnote 22 continued

make someone $1.7 \mathrm{~m}$ tall count as tall. Nothing of what $\mathrm{I}$ have said so far attempts against the idea that some ordinary disputes exhibit metalinguistic conflicts. notion of a metalinguistic conflict cannot serve as a replacement for the characterization in Disagreement in Content. After all, we want to capture the idea that, very often, people will disagree about the facts that they take an utterance to be about, and not only about the way in which the words in the utterance should be used. 
that it would be very likely for the participants in a dispute to take the exact same proposition to be the truth-conditional content of the utterance their dispute is about.

Elsewhere (Abreu Zavaleta 2019) I have argued at length against implementations of these strategies involving the notion of naturalness, common ground, and social externalism. For the sake of brevity, here I consider only a general line of reasoning appealing to the latter. ${ }^{23}$

Social externalism is the view that differences in an individual's social environment may produce differences in the contents of that individual's thoughts, beliefs, and so on. ${ }^{24}$ For instance, according to social externalism, people with the same internal states-e.g. people with exactly the same brain states-may have thoughts with different contents on account of belonging to different communities. To use one of Burge's famous examples (see Burge 1979), suppose Anna thinks she has arthritis in her thigh. According to Burge, if Anna had been in the same brain state but belonged to a somewhat different community, one in which the word 'arthritis' denoted tharthritis rather than arthritis, her thought would have been about thartritis and not about arthritis.

Some opponents of Variance may think that, given social externalism, it is very likely that members of the same linguistic community have the same beliefs about the truth-conditional content of most utterances. Those opponents' line of thought may go as follows. If social externalism is true, then part of what determines someone's beliefs about the truth-conditional content of a given utterance is her social environment, such as the linguistic community that person belongs to. Thus, the opponents of Variance may claim, if two people belong to the same linguistic community, they are very likely to have the same beliefs about the truth-conditional content of any given utterance on account of belonging to the same linguistic community. Since most people who engage in disputes with one another belong to the same linguistic community — say, the community of speakers of the language in which the dispute takes place - they will have the same beliefs about the truth-conditional content of the utterances involved in their conversation.

This line of reasoning overestimates the extent to which social environment determines our beliefs about an utterance's truth-conditional content, even if social externalism is true. If social externalism is true, the linguistic community a person belongs to plays a role in determining those beliefs by determining the content of that person's internal states (e.g. brain states). It does not follow that, if social externalism is true, any two members of the same linguistic community will have the same beliefs about what proposition is the truth-conditional content of a certain utterance. For, even if social externalism is true, different members of the same linguistic community may have different beliefs about an utterance's truth-conditional content (and different beliefs in general) on account of being in different internal states (e.g. being in

\footnotetext{
23 I restrict my attention to social externalism because it is better suited to rejecting the case for Variance than other versions of externalism. However, the remarks that follow can be extrapolated to other versions of externalism.

24 The most prominent defender of social externalism is Burge (1979), Burge (1986), but the general idea may be traced back to Putnam (1975). Williamson (2007) constantly appeals to social externalism in his attacks against analyticity. See Ludlow (1995, 1997), Pollock (2015), Wikforss (2001) for criticism of social externalism.
} 
different brain states). Thus, even if social externalism is true, the fact that two people belong to the same linguistic community does not by itself make it likely that they have the same beliefs about a given utterance's truth-conditional content, since the fact that two people belong to the same linguistic community does not make it likely that they are in the same internal states (e.g. brain states), or internal states that are equivalent in the relevant ways. ${ }^{25}$

For example, suppose that Anna is in brain state $x$. If social externalism is true, then Anna's social environment may determine that the fact that Anna is in brain state $x$ entails that she believes that her utterance of (2) has the truth-conditional content that Carla is at least $1.8 \mathrm{~m}$ tall. And if Bob is also in brain state $x$ and his social environment is the same as Anna's, then social externalism may entail that Bob also believes that Anna's utterance of (2) has the truth-conditional content that Carla is at least $1.8 \mathrm{~m}$ tall.

What Anna and Bob's social environment cannot determine is which particular brain states Anna and Bob are in. Even if Anna and Bob have the same social environment, it could easily happen that Anna is in brain state $x$ and Bob is in brain state $y$, where $y$ is such that Anna and Bob's social environment determines that anyone in brain state $y$ believes that the truth-conditional content of Anna's utterance is the proposition that Carla is at least $1.81 \mathrm{~m}$ tall. Presumably, nearly every utterance is such that any two language users could easily have been in brain states which, in combination with the same social environment, determine different beliefs about that utterance's truthconditional content. Thus, even if social externalism is true, Variance still holds.

Objectors may reply that the version of social externalism I am considering is too weak, for it only states that social environment partly determines the content of people's beliefs. Those objectors may instead want to adopt a version of social externalism that entails:

Strong Social Externalism (SSE): For any utterance U, if U as used by community C has the truth-conditional content $\mathrm{P}$, then all members of $\mathrm{C}$ believe that $\mathrm{U}$ has the truth-conditional content P.

To the best of my knowledge, no one has defended a version of social externalism that entails SSE. This is for good reason, since SSE makes it impossible that members of a given community have mistaken beliefs about the truth-conditional content of utterances made by members of that community, or even that they lack beliefs about those utterances' truth-conditional content. For example, according to SSE, if Bob utters 'Parallelepipeds freak me out', Anna will believe that the truth-conditional content of Bob's utterance is that bodies each of which faces are parallelograms freak Bob out, even if she has never heard the word 'paral-

\footnotetext{
25 These observations apply to externalism about mental content more generally. Externalism about mental content is the thesis that the content of a person's mental states is not entirely determined by that person's intrinsic properties. Clearly, it does not follow from this thesis that any two language users of English are likely to have the same beliefs about the truth-conditional content of a certain utterance, even if they have all the same extrinsic properties. For, even if extrinsic properties play a role in determining mental content, intrinsic properties may play a role too. Thus, despite having the same extrinsic properties, different people may have different beliefs about truth-conditional content on account of having relevantly different intrinsic properties.
} 
lelepiped' before. Or suppose that Bob utters 'I was near the bank yesterday', and that Bob's utterance has the truth-conditional content that Bob was near the river bank the day before the utterance. If SSE is true, Anna cannot mistakenly believe that Bob's utterance instead had the truth-conditional content that Bob was near a certain financial institution the day before the utterance. These consequences are unacceptable.

\section{What does it take for a dispute not to be merely verbal?}

My preferred solution to the puzzle consists in rejecting Disagreement in Content and replacing it with a new characterization of non-merely-verbal disputes. As the discussion in Sect. 4 suggests, such a replacement must play two roles: on the one hand, it must put us in a position to explain why typical disputes are not merely verbal; on the other, it must do so while capturing the idea that non-merely-verbal disputes exhibit conflicts between the disputants' beliefs about the facts they take the disputed utterance to be about. The problem with Disagreement in Content, Factual Conflicts and Cloudy Conflicts is that they can't play the first of these two roles, while the problem with Multiple Rejection and Pseudo-conflicts is that they cannot play the second one. As we will see later on, my preferred solution can play both roles.

Before proceeding, it will be helpful to introduce an abbreviation. From now on, when I say that a given language user associates a given proposition with a given utterance, what I mean is that that language user believes that that proposition is that utterance's truth-conditional content. With this in mind, my proposal is to replace Disagreement in Content with:

Partly Factual Conflicts: A dispute between parties A and B over the truth of an utterance $U$ is not merely verbal if and only if, where $P$ is the proposition $\mathrm{A}$ associates with $\mathrm{U}$ and $\mathrm{Q}$ is the proposition $\mathrm{B}$ associates with $\mathrm{U}, \mathrm{P}$ and $\mathrm{Q}$ have at least one actual truthmaker in common if one of them is true, and at least one actual falsitymaker in common if one of them is false. ${ }^{26}$

Roughly, according to Partly Factual Conflicts, a dispute over an utterance's truth is not merely verbal just in case there is at least one fact which makes all the propositions

\footnotetext{
26 I am assuming that speakers don't usually have beliefs about which truthmakers (falsitymakers) obtain for the proposition they associate with a given utterance. Should speakers actually form such beliefs, one could amend the present proposal as follows: a dispute over $U$ is not merely verbal iff (a) the propositions that the parties to the dispute associate with $U$ have an actual truthmaker in common if one of them is true, and an actual falsitymaker in common if one of them is false, or (b) there is some possible state of affairs which is either a possible truthmaker for all the propositions the parties to the dispute associate with $\mathrm{U}$, or a falsitymaker for all the same propositions, and such that some party to the dispute believes that state of affairs to obtain. Nothing in what follows hinges on this amendment.
} 


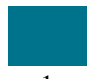

1

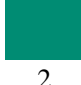

2

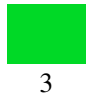

3

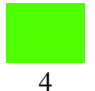

4
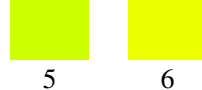

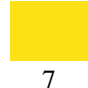

Fig. 2 Some colors

the parties to the dispute associate with that utterance true, or which makes them all false. ${ }^{27,} 28$

Later I will say more about how truthmaking and falsitymaking should be understood; for the time being, let's see how Partly Factual Conflicts characterizes the conflicts that non-merely-verbal disputes exhibit. To this end, consider the following examples.

Suppose that Anna believes that the word 'green' denotes things of colors 2-5, whereas Bob believes that it denotes things of colors 3-6 (see Fig. 2). Anna just got a new house and is describing it to Bob. Referring to her house, she utters:

(8) It is green.

27 Somewhat in passing, Sidelle (2007) offers a similar view of non-merely-verbal disputes; according to Sidelle, disputes are not merely verbal when the objects that the dispute is about are (or fail to be) in the extension of the relevant predicates on all the parties' interpretations of those predicates: "While not wanting to fully commit myself to this analysis, it seems like we have everything we want here on a supervaluational approach. Generally speaking, disagreements (and agreements) can be genuine when the cases [under dispute] are in the range of agreement in the competing interpretations" (Sidelle 2007, p. 99). At least at first sight, this view seems to make mistaken predictions: on this view, if Carla is $1.9 \mathrm{~m}$ tall and weighs $70 \mathrm{~kg}$, then a dispute over Anna's utterance of 'Carla is tall' is not merely verbal even if the proposition Anna associates with her utterance is that Carla is at least $1.8 \mathrm{~m}$, but the proposition that Bob associates with the same utterance is that Carla weighs at least $60 \mathrm{~kg}$. Another way of interpreting Sidelle is as saying that a dispute over a given utterance is not merely verbal when, given what each party to the dispute believes, the utterance is true relative to that party's interpretation of the utterance. This view seems to make the wrong prediction in the following case: suppose Anna and Bob's interpretations of 'Carla is tall' are as in the previous case, that Anna believes that Carla is $1.9 \mathrm{~m}$ tall and weighs $70 \mathrm{~kg}$, and that Bob believes that Carla is $1.6 \mathrm{~m}$ tall and weighs $50 \mathrm{~kg}$. On this interpretation, Sidelle's view would predict that Anna and Bob's dispute is not merely verbal, despite the fact that Anna takes her utterance to be about Carla's height and Bob takes the same utterance to be about Carla's weight. Though Partly Factual Disputes is similar in spirit to Sidelle's approach, the use of truthmaker ideology allows the former to make finer distinctions in the kind of cases just discussed. I believe that the ideology of truthmakers and falsitymakers could also help flesh out Chalmers' (2011) view of "broadly verbal" disputes; I hope to discuss the relation between Chalmers' view and my own in future work.

28 Thanks to an anonymous reviewer for bringing up potential problems with presupposition. Suppose that Anna utters 'Carla stopped smoking' and Bob replies 'No, she didn't', and that both Anna and Bob associate the proposition that Carla stopped smoking with Anna's utterance. Suppose, furthermore, that Carla never started smoking. Anna and Bob's dispute is not merely verbal, but, according to popular accounts of presupposition failure, the proposition that Carla stopped smoking is truth-valueless, and therefore has no actual truthmakers or falsitymakers, so it seems that Partly Factual Conflicts fails to predict that the dispute is not merely verbal. One thing to note is that Partly Factual Conflicts states that a dispute is not merely verbal just in case if one of the propositions involved is false, they share a falsitymaker, and if one of them is true, they share a truthmaker. Using a basic account of the indicative conditionals on which a conditional is true just in case the consequent is true in every closest world in which the antecedent is true, Partly Factual Conflicts does predict that the dispute is not merely verbal. Alternatively, one could adopt a Russellian line of presupposition failure and claim that, in cases of presupposition failure, the falsitymaker for the proposition with a failed presupposition just is the falsitymaker for the presupposition. 
Fig. 3 Some areas of Brooklyn

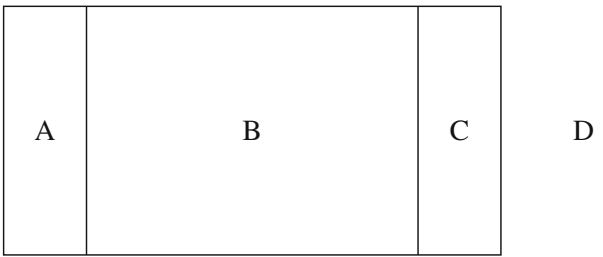

Suppose for simplicity that Anna and Bob both believe that 'it' as it occurred in Anna's utterance refers to $H$, Anna's house. Then Anna will associate (9) with her utterance, whereas Bob will associate (10) with the same utterance:

(9) $\mathrm{H}$ is one of colors 2-5,

(10) $\mathrm{H}$ is one of colors 3-6.

According to Partly Factual Conflicts, though (9) and the negation of (10) are logically compatible, there are certain circumstances in which a dispute between Anna and Bob over the truth of Anna's utterance would not be merely verbal. For example, suppose that Anna's house is in fact color 4. According to the present view, Anna and Bob's dispute is not merely verbal in that scenario insofar as the exact same fact - the fact that Anna's house is color 4-is responsible for the truth of both (10) and (9). Accordingly, given that Anna's house is color 4, it cannot be the case that Anna knows that (9) is true and Bob knows that (10) is false. In this way, there is an epistemic conflict between Anna and Bob's respective beliefs that (9) is true and that (10) is false.

Here is another example. Anna and Bob use 'Dumbo' to refer to different areas of Brooklyn. Anna uses 'Dumbo' to refer to the area constituted by areas A and B, and Bob uses 'Dumbo' to refer to the area constituted by B and C (see Fig. 3). Bob wants to meet with Anna, so he calls her to ask where she is. Anna replies:

(11) I'm in Dumbo.

Because of the difference in their beliefs about what area is denoted by 'Dumbo', Anna and Bob associate different propositions with Anna's utterance. Anna associates (12) with her utterance, whereas Bob associates (13) with it:

(12) Anna is in area A or area B,

(13) Anna is in area B or area C.

As it happens, just as Anna utters (11), she is on the corner of Gold St. and York St., which is in area D. Bob, who sees Anna from afar, replies to Anna 'no, you're not'.

Though the truth of (12) is in principle compatible with the falsity of (13), there is a fact responsible for the falsity of both. In particular, both of those propositions are false in virtue of the fact that Anna is at the corner of Gold and York. Thus, according to Partly Factual Disputes, Anna and Bob's dispute in this scenario is not merely verbal. And, since Anna in fact is in the corner of Gold and York, one cannot know both that (12) is true and that (13) is false. In this respect, Anna and Bob's dispute exhibits an epistemic conflict.

My view is that typical disputes are more or less like Anna and Bob's disputes in these two examples. On the one hand, given the truth of Variance, typical disputes over 
the truth of a given utterance are such that there is no proposition all the disputants associate with that utterance. On the other, those disputes are not merely verbal insofar as there is at least one fact responsible for the truth (falsity) of the propositions the different parties to the dispute associate with the utterance under dispute. If this is true, the conflicts that characterize non-merely-verbal disputes are of an epistemic kind: if Partly Factual Conflicts is true, it is necessarily the case that if A and B have a dispute over the truth of $\mathrm{U}, \mathrm{A}$ associates $\mathrm{P}$ with $\mathrm{U}, \mathrm{B}$ associates $\mathrm{Q}$ with $\mathrm{U}$, and their dispute is not merely verbal, then it is not the case that $\mathrm{A}$ knows that $\mathrm{P}$ is true and $\mathrm{B}$ knows that $\mathrm{Q}$ is false, and it is not the case that $\mathrm{A}$ knows that $\mathrm{P}$ is false and $\mathrm{B}$ knows that $\mathrm{Q}$ is true. ${ }^{29}$ Furthermore, this kind of epistemic conflict will be grounded entirely on facts that $A$ and $B$ both deem relevant to the truth of $U$ in the following sense: if $P$ is true and B knows the facts that make it true, she could not reasonably believe that $\mathrm{Q}$ is false; similarly, if Q is false and A knows the facts that make it false, she could not reasonably believe that $\mathrm{P}$ is true. In this way, Partly Factual Conflicts accounts for the fact that non-merely-verbal disputes exhibit conflicts between the disputants' beliefs about the facts they take the disputed utterance to be about; if Partly Factual Conflicts is true, those conflicts are of an epistemic nature. ${ }^{30}$

This leaves us only with the task of showing how Partly Factual Conflicts solves the puzzle from Sect. 3. In order to accomplish this task, it will be useful to elaborate on the notions of truthmaking and falsitymaking as used in truthmaker semantics (for versions of truthmaker semantics, see Fine 2012, 2016; Yablo 2014).

I will roughly follow Fine and take possible truthmakers and falsitymakers to be possible states of affairs (or possible states, for short), as opposed to possible worlds. Unlike possible worlds, which settle the truth-value of absolutely every proposition, most possible states of affairs settle the truth-value of only some propositions. For instance, a possible state of affairs that settles the truth value of it rains in Nepal (i.e. a state of affairs in which that proposition is true, or a state of affairs in which that proposition is false) need not settle the truth-value of Anna is $1.7 \mathrm{~m}$ tal1. Also unlike possible worlds, possible states can stand in parthood relations. For instance, a state in which it rains lightly in Nepal is part of a state in which it rains lightly in Nepal and Anna is $1.7 \mathrm{~m}$ tall, which in turn is part of a state in which it rains lightly in Nepal, Anna is $1.7 \mathrm{~m}$ tall, and Bob weighs $70 \mathrm{~kg} .{ }^{31}$

\footnotetext{
29 This is because if A and B's dispute is not merely verbal, then either (a) there is at least one fact fully responsible for the truth of both $\mathrm{P}$ and $\mathrm{Q}$, in which case $\mathrm{B}$ doesn't know that $\mathrm{Q}$ is false and A doesn't know that $\mathrm{P}$ is false, or (b) there is at least one fact fully responsible for the falsity of both $\mathrm{P}$ and $\mathrm{Q}$, in which case A doesn't know that $\mathrm{P}$ is true and B doesn't know that $\mathrm{Q}$ is true.

30 Note that, in appealing to actual (as opposed to merely possible) truthmakers and falsitymakers, Partly Factual Conflicts embodies a kind of externalism about what it is for a dispute not to be merely verbal. In particular, whether a given dispute is not merely verbal depends in part on what the actual truthmakers or falsitymakers of certain propositions are, and this ultimately depends on how the world is rather than on purely intrinsic relations between propositions. See above, p. 18 for the case that we must embrace some form of externalism in order to account for the epistemic significance of non-merely-verbal disputes.

31 More precisely, we can think of possible states of affairs as partial functions from propositions to truthvalues. For example, if $\mathrm{P}$ and $\mathrm{Q}$ are different propositions, one possible state of affairs will be the function that assigns truth to $\mathrm{P}$, another the function that assigns falsehood to $\mathrm{Q}$, and yet another the function that assigns truth to $\mathrm{P}$ and falsehood to Q. If we think of states of affairs in this way, when I say that $s$ is a state in which $\mathrm{P}$ is true, what I mean is just that $s(\mathrm{P})=\mathrm{T}$. If we think of states of affairs in this way, we can define the parthood relation as follows: if $s$ and $s^{\prime}$ are possible states of affairs, then $s \leq s^{\prime}$ ( $s$ is part of
} 
A proposition's possible truthmakers (falsitymakers) are the possible states in which that proposition is true (false), and such that every part of the state plays a role in guaranteeing the proposition's truth (falsehood). For example, a state in which Anna is $1.7 \mathrm{~m}$ tall is a possible truthmaker for both the proposition Anna is $1.7 \mathrm{~m}$ tall and the proposition Anna is at least $1.6 \mathrm{~m}$ tall. On the other hand, a state in which Anna is $1.7 \mathrm{~m}$ tall and it rains lightly in Nepal is not a truthmaker for Anna is $1.7 \mathrm{~m}$ tall or for Anna is at least $1.7 \mathrm{~m}$ tall, since it contains a part that plays no role in determining their truth-value-namely, the part in which it rains lightly in Nepal. A proposition's actual truthmakers (falsitymakers) are that proposition's possible truthmakers (falsitymakers) which in fact obtain.

In general, if a proposition's truth depends on an object's properties along certain dimensions - e.g. color, height, weight, degree of similarity to a paradigmatic case of a certain class, etc. - that proposition's possible truthmakers (falsitymakers) are the possible states which (a) determine that object's maximally specific properties along those dimensions and nothing else, and (b) guarantee the proposition's truth (falsity) were they to obtain. For example, the possible truthmakers for the proposition Anna is at least $1.7 \mathrm{~m}$ tall will be the possible states of affairs in which Anna is $1.7 \mathrm{~m}$ tall, in which Anna is $1.8 \mathrm{~m}$ tall, and so on; its possible falsitymakers will be the possible states in which Anna is $1.69 \mathrm{~m}$ tall, $1.687 \mathrm{~m}$ tall, and so on.

With this in mind, recall the case for Variance. For nearly every utterance, there is an enormous number of equally natural and extremely similar propositions any language user could easily have associated with that utterance. Given the huge number of such propositions, even small differences in the evidence that determines what proposition to associate with the utterance, in the way someone is attuned to that evidence, and so on, are likely to produce differences in what proposition that person associates with that utterance. And since different language users rarely have the exact same evidence or are attuned to the evidence in exactly the same way, it is extremely unlikely that they associate the same proposition with the utterance in question.

The case for Variance shows that, for nearly every utterance, no two language users associate the same proposition with that utterance. What the argument does not show is that the propositions those language users associate with a given utterance will be so different that they fail to share at least one actual truthmaker or at least one falsitymaker. Anna's dispute with Bob illustrates this: in a possible world in which Anna's house is color 4, the propositions Anna and Bob associate with Anna's utterance of (8) will have the same actual truthmaker despite being logically independent. More generally, it is entirely compatible with Variance that typical disputes are such that the propositions the disputants associate with the utterance under dispute share at least one actual truthmaker or at least one actual falsitymaker-and so, it is compatible with Variance that typical disputes are not merely verbal by the lights of Partly Factual Disputes. Now, this only shows that, given Variance and Partly Factual Conflicts, typical disputes need not be merely verbal. But, given the present framework, we can also show that,

Footnote 31 continued

$\left.s^{\prime}\right)$ just in case, for all propositions $\mathrm{P}$, if $s(\mathrm{P})$ is defined, then $s(\mathrm{P})=s^{\prime}(\mathrm{P})$. I'm assuming that propositions are sufficiently finely individuated so that, if $\mathrm{P}$ and $\mathrm{Q}$ are logically independent propositions, then $\mathrm{P} \vee \neg \mathrm{P}$ is different from $\mathrm{Q} \vee \neg \mathrm{Q}$. For further details on my preferred version of truthmaker semantics, see Abreu Zavaleta (2018, ch.2). 
at least in the case of simple predications of the form $\ulcorner\mathrm{j}$ is $\mathrm{F}\urcorner$ (where $\mathrm{j}$ is a proper name and $\mathrm{F}$ is a predicate), typical disputes really are not merely verbal. ${ }^{32}$

Above (p. 26) I said that if the truth of a given proposition depends on an object's properties along certain dimensions, then that proposition's possible truthmakers (falsitymakers) are possible states of affairs which (a) determine that object's maximally specific properties along those dimensions and nothing else, and (b) guarantee the proposition's truth (falsity) were they to obtain. Thus, if the truth of two propositions depends on the same object's properties along the same dimensions, those propositions will have the same actual truthmakers if one of them is true, and the same actual falsitymakers if one of them is false.

Now, an important assumption in the case for Variance is that the truth of the various truth-conditional content candidates an utterance has depends on the same object's properties along the same dimensions. From this assumption and the observations in the last paragraph, it follows that if two truth-conditional content candidates for the same utterance have the same truth-value, they either have the same actual truthmakers (if they are true), or they have the same actual falsitymakers (if they are false). And since (by assumption) the difference between truth-conditional content candidates for the same utterance is very minimal, it is very likely for any two truth-conditional content candidates for the same utterance to have the same truth-value. Accordingly, it is very likely for any two-truth-conditional candidates to have the same actual truthmakers or the same falsitymakers.

For example, consider the propositions

(14) $\mathrm{x}$ is at least $11 \mathrm{~m}$ tall

(15) $\mathrm{x}$ is at least $11.1 \mathrm{~m}$ tall.

The truth of these two propositions depends exclusively on x's height. Accordingly, one possible truthmaker for both (14) and (15) will be a state of affairs in which $\mathrm{x}$ is exactly $11.5 \mathrm{~m}$ tall and nothing else happens; another will be a state of affairs in which $\mathrm{x}$ is exactly $13 \mathrm{~m}$ tall and nothing else happens; etc. On the other hand, one possible falsitymaker for both (14) and (15) will be a state of affairs in which $\mathrm{x}$ is $9 \mathrm{~m}$ tall and nothing else happens; another will be a state in which $\mathrm{x}$ is $3 \mathrm{~m}$ tall and nothing else happens, and so on. In fact, the only possible states that are possible truthmakers for one of (14) and (15) but not for the other will be states in which $\mathrm{x}$ is less than $11.1 \mathrm{~m}$ tall, but at least $11 \mathrm{~m}$ tall. Those same states will be the ones that are possible falsitymakers for one of (14) and (15) but not for the other. And, since it is much more likely that $\mathrm{x}$ has some height below $11 \mathrm{~m}$ or above $11.1 \mathrm{~m}$ than that it has a height exactly between 11 and $11.1 \mathrm{~m}$, it is very likely that (14) and (15) have the same actual truthmakers or the same actual falsitymakers. Thus, if Partly Factual Conflicts is true, any dispute whose participants respectively associate (14) and (15) with the disputed utterance is very likely not to be merely verbal. More generally, if Partly Factual Disputes is true, if the participants in a dispute associate truth-conditional content candidates of the

\footnotetext{
32 I restrict my attention to these predications for the sake of brevity. For an extension of these arguments to Boolean compounds, see Abreu Zavaleta (2018, ch.3). Ultimately, the case that typical disputes are not merely verbal given Partly Factual Conflicts will depend on a full implementation of truthmaker semantics for natural language.
} 
kind used in the case for Variance with the disputed utterance, their dispute is very likely not to be merely verbal.

As the discussion suggests, Partly Factual Conflicts is preferable to the alternatives discussed in Sect. 4 as a replacement for Disagreement in Content. On the one hand, unlike Factual Conflicts and Cloudy Conflicts, it delivers the result that typical disputes (at least in the case of simple predications) are not merely verbal. On the other, unlike Multiple Rejection and Pseudo-conflicts, it does justice to the idea that non-merelyverbal disputes exhibit conflicts in the disputants' beliefs about substantive facts. According to Partly Factual Conflicts, those conflicts are of an epistemic kind: if one of the disputants knows that the proposition she associates with the disputed utterance is true, then the other doesn't know that the proposition she associates with the same utterance is false, and if one of the disputants knows that the proposition she associates with the disputed utterance is false, then the other doesn't know that the proposition she associates with the same utterance is true. ${ }^{33}$

\section{Objections and replies}

\subsection{Evaluative discourse}

Objection. Perhaps Partly Factual Disputes delivers the right results when it comes to predicates like 'tall' and 'green', or with proper names like 'Dumbo'. However, it is not clear how to extend the view to cases involving evaluative language. If Anna utters 'salad is tasty' and Bob replies 'no, it isn't', does the view predict that the dispute is merely verbal? If it does, it is not clear that the view does justice to the intuitive notion of a non-verbal dispute. Similar issues arise in the case of disputes about utterances involving aesthetic and normative vocabulary. ${ }^{34}$

\footnotetext{
33 Some people may worry that even Partly Factual Conflicts is too strong. On the basis of the case for Variance, those people may endorse a further thesis we may call Uncertainty: nearly every utterance is such that there is no proposition which any language user believes to be that utterance's truth-conditional content. According to them, ordinary language users will typically be undecided as to which of a large number of propositions is a given utterance's truth-conditional content. If this is so, then nearly every utterance is such that no dispute over its truth exhibits a partly factual conflict. We can address the problem by adapting the present account as follows:

Partly factual conflicts*: A dispute between parties A and B over the truth of an utterance U exhibits a partly factual conflict* just in case:

(i) If one of the propositions A takes to be live candidates for U's truth-conditional content is true, then each of those candidates has an actual truthmaker in common with a proposition B takes to be a live candidate for U's truth-conditional content, and vice versa.

(ii) If one of the propositions A takes to be live candidates for U's truth-conditional content is false, then each of those candidates has an actual falsitymaker in common with a proposition B takes to be a live candidate for U's truth-conditional content, and vice versa.

Given that the truth of the various truth-conditional content candidates an utterance has depends on the same object's properties along the same dimensions, ordinary disputes are likely to exhibit partly factual conflicts*.

34 Thanks to an anonymous reviewer for raising this objection.
} 
Reply. There is an ongoing debate on how to characterize disputes involving evaluative language. Some authors (e.g. Sundell (2011)) claim that disputes involving words like 'tasty' really are verbal: when we engage in them, we do not really disagree about matters of fact; we are only disagreeing about how to use the word 'tasty'. Others (e.g. MacFarlane 2005, 2007, 2014) claim that disputes about taste are not verbal: when Anna utters 'salad is tasty' and Bob rejects Anna's utterance, there is a proposition which one of them believes and the other disbelieves, albeit the truth of that proposition will depend on the perspective from which it is assessed.

To the best of my knowledge, neither position is taken to be dominant over the other in the current literature, so it would not be a disadvantage if Partly Factual Disputes didn't predict that disputes involving predicates of personal taste are merely verbal. That said, it is worth explaining how Partly Factual Disputes's predictions depending on which position one adopts on the debate about predicates of personal taste. And, while I focus on predicates of personal taste, the conclusions below can be extended to aesthetic and normative predicates.

Suppose for example that the propositions which ordinary speakers take utterances involving predicates of personal taste to express are ordinary, non-relativistic propositions. Suppose, furthermore, that a basic kind of contextualism about predicates of personal taste is true: in any given context, any given predicate of personal taste expresses the property of satisfying the contextually determined standard, and what determines that standard are the speaker's preferences. For example, if, relative to Anna's standards, the predicate 'salty' applies to things that are least $0.5 \%$ salt, then when Anna utters 'the soup was salty', her utterance's truth-conditional content is the proposition that a certain soup was at least $0.5 \%$ salt. Now, suppose that Bob utters 'the soup was salty' and believes that his utterance's truth-conditional content is the proposition that a certain soup was at least $0.1 \%$ salt; Anna replies 'no, it wasn't' believing that the truth-conditional content of Bob's utterance is the proposition that the same soup is at least $0.5 \%$ salt.

According to Partly Factual Disputes, whether Anna and Bob's dispute is merely verbal depends on how much salt the soup actually had. If, for example, the soup was $0.2 \%$ salt, then the dispute was merely verbal-since that fact makes it true that the soup was at least $0.1 \%$ salt, but false that the soup was at least $0.5 \%$ salt. But if the soup was $0.6 \%$ salt, then the dispute was not merely verbal, since that fact makes it true both that the soup was at least $0.1 \%$ salt and that the soup was at least $0.5 \%$ salt. Assuming that speakers are typically correct about whether food items they have tried meet their standards for the application of 'salty', the first kind of case will be more common than the second, so Partly Factual Disputes predicts that disputes over utterances involving 'salty' will be typically verbal. In that case, as Sundell (2011) claims, the point of having such disputes is probably to coordinate on how to use the word 'salty', rather than to come to know facts about how much salt some particular food has.

But suppose, on the other hand, that the propositions which ordinary speakers take utterances involving predicates of personal taste are relativistic propositions. For example, according to this approach, in every context the sentence 'the soup is salty' expresses a proposition which is true not at a possible world, but at a pair of a world 
and an assessor. We can represent that proposition as the following function from assessors and possible worlds to truth-values:

(16) $\lambda a . \lambda w$. the soup is salty in $w$ relative to $a$ 's standards of saltiness.

Given Anna and Bob's respective standards, if the soup is actually $0.1 \%$, then (16) is true as assessed by Bob, but false assessed by Anna. Should we adopt this position, whether a certain possible state of affairs counts as a truthmaker (falsitymaker) for (16) depends on the perspective of the assessor: relative to Bob, states of affairs in which the soup is $0.1 \%$ salt are truthmakers for (16); relative to Anna, those same states are falsitymakers for (16).

Now, consider once more Anna and Bob's dispute over Bob's utterance of 'the soup is salty'. According to Partly Factual Disputes, if Anna and Bob both believe that that utterance expresses (16), then, relative to every pair of a possible world and an assessor, their dispute will not be merely verbal. For, relative to any such pair, (16) has the same truthmakers (falsitymakers) as itself. More generally, assuming that typical speakers take utterances involving predicates of personal taste to express relativistic propositions, Partly Factual Disputes predicts that disputes over those utterances are not merely verbal. ${ }^{35}$ In this way, Partly Factual Disputes can be made coherent with both views like Sundell's and views like MacFarlane's on disputes involving taste predicates. Similar observations hold for disputes about evaluative predicates more generally.

\subsection{Accidentally non-verbal disputes}

Objection. According to Partly Factual Disputes, disputes are not merely verbal if the propositions the parties to the dispute associate with the utterance that the dispute is about overlap in actual truthmakers or in actual falsitymakers. But then, if a dispute is not merely verbal, that would seem to be merely accidental. So what is the nature of the disputes that the account predicts to be non-merely-verbal, given that they are in some sense accidental? Can they be the grounds for the transmission of knowledge or the formation of reliable plans? ${ }^{36}$

Reply. It is not the case that, if Partly Factual Disputes is true, then whether a given dispute is merely verbal is accidental. Consider for instance Anna and Bob's dispute over Anna's utterance of (2). There are many equally eligible propositions which each of Anna and Bob could easily have associated with (2), each involving a slightly different cutoff point for whether to count Anna as "tall"- those propositions will include, for instance, the proposition that Carla is at least $1.8 \mathrm{~m}$ tall, the proposition that Carla is at least $1.801 \mathrm{~m}$ tall, the proposition that Carla is at least $1.81 \mathrm{~m}$ tall, and so on. Given how similar the eligible propositions are to each other, it is overwhelmingly likely that Anna and Bob associate propositions with (2) which have the same actual truthmakers or the same actual falsitymakers. For example, if Anna associates the proposition that Carla is at least $1.8 \mathrm{~m}$ tall with her utterance of (2), and Bob associates the proposition

\footnotetext{
35 Note that relativism about truth could be used to solve the puzzle from Sect. 3, but only at the cost of assuming relativism about nearly every domain of discourse. This, I take it, is not a viable approach.

36 Thanks to an anonymous reviewer for raising this objection.
} 
that Carla is at least $1.81 \mathrm{~m}$ tall with the same utterance, it is overwhelmingly more likely that their dispute over the truth of (2) is not merely verbal than that it is merely verbal-since it is overwhelmingly more likely that Carla is either shorter than $1.8 \mathrm{~m}$ or taller than $1.81 \mathrm{~m}$ than that her height falls somewhere between 1.8 and $1.81 \mathrm{~m}$. Given how much likelier it is that Anna's dispute is not merely verbal than that is merely verbal, it can hardly be considered an accident that Anna and Bob's dispute is not merely verbal.

In fact, if Anna and Bob's dispute is not merely verbal, it will very likely be nonverbal in every nearby world-i.e. it will be reliably non-verbal. For example, suppose that Carla is $1.9 \mathrm{~m}$ tall. Plausibly, Carla's exact height is slightly different heights in nearby worlds, but those small differences won't bring about differences in the status of Anna and Bob's dispute as non-merely verbal. For example, if Carla is actually $1.9 \mathrm{~m}$ tall, there may be nearby worlds in which she is $1.91 \mathrm{~m}$ tall, and nearby worlds in which she is $1.899 \mathrm{~m}$ tall; in both scenarios, Anna and Bob's dispute would still not be merely verbal. More generally, if the actual truthmakers (falsitymakers) which the propositions Anna and Bob respectively associate with Anna's utterance of (2) are robustly within the range of truthmakers (falsitymakers) for those propositions, Anna and Bob's dispute will be non-merely-verbal in all nearby worlds.

This brings us to the nature of the disputes which Partly Factual Disputes predicts to be non-merely-verbal. In Sect. 6 (p. 25) I argued that those disputes robustly exhibit epistemic conflicts: if Partly Factual Disputes is true, then, necessarily, if A and B's dispute over the truth of $U$ is not merely verbal, then it's not the case that A knows that the proposition she associates with $\mathrm{U}$ is true and $\mathrm{B}$ knows that the proposition she associates with $\mathrm{U}$ is false, and it is not the case that A knows that the proposition she associates with $\mathrm{U}$ is false and B knows that the proposition she associates with $\mathrm{B}$ is false (see fn. 29 for proof). The observations in the present section complement this claim: if, as it is likely, Anna and Bob's dispute over the truth of Anna's utterance of (2) is reliably non-verbal, it follows that that dispute reliably exhibits an epistemic conflict between Anna and Bob's beliefs about Carla's height. Whether that is enough for such a dispute to ground the transmission of knowledge or the formation of reliable plans may be up for debate, but for present purposes it should suffice to show that reliability is not an issue.

\section{Conclusion}

In this paper I presented a puzzle about disagreement. I argued that, given a seemingly plausible characterization of non-merely-verbal disputes, non-merely-verbal disputes are extremely rare. This is troubling: we would expect typical disputes over the truth of an utterance to reflect conflicts between the disputants' beliefs about the facts they take the utterance under dispute to be about. Yet, as the puzzle has it, typical disputes are, in a way, purely verbal.

This puzzle has interesting consequences for other debates, such as the debate between contextualists and anti-contextualists. Contextualists claim that many words besides the standard indexicals (e.g. 'I', 'here, 'now') are context-sensitive; anticontextualists deny this. According to anti-contextualists like Cappelen and Lepore 
(2005), contextualism cannot account for the existence of genuine cross-discourse disagreements. They claim that if contextualism is true, "it would be a miracle if speakers in different contexts were ever able to agree, disagree, or more generally, share contents" (p. 124). According to theorists like Cappelen and Lepore, if contextualism is true then people who find themselves in different contexts would rarely associate the same propositions with a given utterance, in which case genuine cross-contextual disagreements, agreements, and communication more generally, will be very rare.

The discussion in this paper puts contextualists in a position to neutralize this objection. Objections from lost disagreement presuppose views of disagreement similar to Disagreement in Content or Factual Conflicts. Yet, as the discussion in this paper shows, those accounts are too stringent: in conjunction with Variance, they entail that non-merely-verbal disagreements are rare. In this way, arguments from lost disagreement seem to pose more of a problem for views like Disagreement in Content and Factual Conflicts than for contextualism itself. ${ }^{37}$ Since the considerations in favor of Variance apply even to terms that anti-contextualists take to be context-independent, anti-contextualists have little advantage over contextualists in accounting for disagreement.

Needless to say, it is one thing to show that objections from lost disagreement do not pose special problems for contextualism, and quite another to show how contextualists can explain cross-contextual disagreements. Partly Factual Disputes can be helpful here. Should contextualists endorse this thesis, that would put them in a position to explain what kind of conflicts we can expect cross-contextual disagreements to exhibit. In this way, further study of the puzzle I presented in this paper can not only improve our understanding of disagreement, but also contribute to settling the debate between contextualists and anti-contextualists.

Acknowledgements Thanks to Cian Dorr, Dmitri Gallow, Japa Pallikkathayil, Jim Pryor, Stephen Schiffer, James Shaw, Nandi Theunissen, and three anonymous reviewers for helpful discussion and comments. Thanks especially to Erica Shumener for helpful comments on multiple versions of this paper.

Funding Open access funding provided by Umea University.

Open Access This article is licensed under a Creative Commons Attribution 4.0 International License, which permits use, sharing, adaptation, distribution and reproduction in any medium or format, as long as you give appropriate credit to the original author(s) and the source, provide a link to the Creative Commons licence, and indicate if changes were made. The images or other third party material in this article are included in the article's Creative Commons licence, unless indicated otherwise in a credit line to the material. If material is not included in the article's Creative Commons licence and your intended use is not permitted by statutory regulation or exceeds the permitted use, you will need to obtain permission directly from the copyright holder. To view a copy of this licence, visit http://creativecommons.org/licenses/by/4.0/.

\footnotetext{
37 Criticisms of the view of disagreement Cappelen and Lepore implicitly endorse are not new. For example, Sundell (2011) argues that disagreements about taste are really disagreements about what standard of taste to adopt and claim that such disagreements deserve to be called genuine; Huvenes (2012) claims that a disagreement may count as "genuine" even if they are merely verbal by the lights of Disagreement in Content and Factual Conflicts; Khoo and Knobe (2016) adopt a similar line on disagreements involving moral terms. What is new is the observation that if Factual Conflicts or Disagreement in Content were true, then there would be nearly no genuine disagreements about non-linguistic matters.
} 


\section{References}

Abreu Zavaleta, M. (2018). Semantic variance. Ph.D. thesis, New York University.

Abreu Zavaleta, M. (2019). Communication and variance. Topoi,. https://doi.org/10.1007/s11245-01909648-3.

Barker, C. (2002). The dynamics of vagueness. Linguistics and Philosophy, 25(1), 1-36.

Beddor, B., \& Egan, A. (2018). Might do better: Flexible relativism and the QUD. Semantics and Pragmatics, 11, 1-7. https://doi.org/10.3765/sp.11.7.

Buchanan, R. (2010). A puzzle about meaning and communication. Noûs, 44(2), 340-371.

Burge, T. (1979). Individualism and the mental. Midwest Studies in Philosophy, 4(1), 73-122.

Burge, T. (1986). Intellectual norms and foundations of mind. Journal of Philosophy, 83(December), 697720.

Cappelen, H., \& Hawthorne, J. (2009). Relativism and monadic truth. Oxford: Oxford University Press.

Cappelen, H., \& Lepore, E. (2005). Insensitive semantics: A defense of semantic minimalism and speech act pluralism. Hoboken: Wiley-Blackwell.

Chalmers, D. J. (2011). Verbal disputes. Philosophical Review, 120(4), 515-566.

Cresswell, M. J. (1977). The semantics of degree. In B. Partee (Ed.), Montague grammar (pp. 261-292). New York: Academic Press.

Dorr, C., \& Hawthorne, J. (2014). Semantic plasticity and speech reports. Philosophical Review, 123(3), 281-338.

Egan, A. (2010). Disputing about taste. In T. Warfield \& R. Feldman (Eds.), Disagreement (pp. 247-286). Oxford: Oxford University Press.

Fine, K. (2012). Counterfactuals without possible worlds. Journal of Philosophy, 109(3), 221-246.

Fine, K. (2016). Angellic content. Journal of Philosophical Logic, 45(2), 199-226.

Foster, J. (1976). Meaning and truth theory. In G. Evans \& J. McDowell (Eds.), Meaning and truth, essays in semantics (pp. 1-32). New York: Clarendon Press. (chap 1).

Heim, I. (2000). Degree operators and scope. In B. Jackson \& T. Matthews (Eds.), Semantics and linguistic theory 10 (pp. 40-64). NIthaca, Y: Cornell University.

Heim, I., \& Kratzer, A. (1998). Semantics in generative grammar. Hoboken: Blackwell.

Hirsch, E. (1993). Dividing reality. Oxford: Oxford University Press.

Huvenes, T. T. (2012). Varieties of disagreement and predicates of taste. Australasian Journal of Philosophy, 90(1), 167-181.

Jenkins, C. S. I. (2014). Merely verbal disputes. Erkenntnis, 79(S1), 11-30.

Kennedy, C. (2007). Vagueness and grammar: The semantics of relative and absolute gradable adjectives. Linguistics and Philosophy, 30(1), 1-45.

Kennedy, C., \& McNally, L. (2005). Scale structure, degree modification, and the semantics of gradable predicates. Language, 81(2), 345-381.

Khoo, J. (2020). Quasi indexicals. Philosophy and Phenomenological Research, 100, $26-53$.

Khoo, J., \& Knobe, J. (2016). Moral disagreement and moral semantics. Noûs, 52, 109-143.

Larson, R., \& Segal, G. (1995). Knowledge of meaning: An introduction to semantic theory. Cambridge: MIT Press.

Lewis, D. (1975). Languages and language. In K. Gunderson (Ed.), Minnesota studies in the philosophy of science (pp. 3-35). Minneapolis: University of Minnesota Press.

Ludlow, P. (1995). Externalism, self-knowledge, and the prevalence of slow-switching. Analysis, 55(1), 45-49.

Ludlow, P. (1997). On the relevance of slow switching. Analysis, 57(4), 285-286.

Ludlow, P. (2014). Living words: Meaning underdetermination and the dynamic lexicon. Oxford: Oxford University Press.

MacFarlane, J. (2005). Making sense of relative truth. Proceedings of the Aristotelian Society, 105(3), 321-339.

MacFarlane, J. (2007). Relativism and disagreement. Philosophical Studies, 132(1), 17-31.

MacFarlane, J. (2014). Assessment sensitivity: Relative truth and its applications. Oxford: Oxford University Press.

Pollock, J. (2015). Social externalism and the problem of communication. Philosophical Studies, 172(12), 3229-3251.

Portner, P. (2005). What is meaning?: fundamentals of formal semantics. Hoboken: Blackwell.

Putnam, H. (1975). The meaning of 'meaning'. Minnesota Studies in the Philosophy of Science, 7, 131-193. 
Schiffer, S. (1981). Indexicals and the theory of reference. Synthese, 49(1), 43-100.

Sidelle, A. (2007). The method of verbal dispute. Philosophical Topics, 35(1/2), 83-113.

Sider, T. (2006). Quantifiers and temporal ontology. Mind, 115(457), 75-97.

Sundell, T. (2011). Disagreements about taste. Philosophical Studies, 155(2), 267-288.

Vermeulen, I. (2018). Verbal disputes and the varieties of verbalness. Erkenntnis, 83(2), 331-348.

von Fintel, K., \& Gillies, A. S. (2011). 'might' made right. In A. Egan \& B. Weatherson (Eds.), Epistemic modality (pp. 108-130). Oxford: Oxford University Press.

Wikforss, A. M. (2001). Social externalism and conceptual errors. Philosophical Quarterly, 51(203), 217231.

Williamson, T. (2007). The philosophy of philosophy. Hoboken: Blackwell.

Yablo, S. (2014). Aboutness. Princeton: Princeton University Press.

Publisher's Note Springer Nature remains neutral with regard to jurisdictional claims in published maps and institutional affiliations. 